\title{
Índice de vulnerabilidade das famílias: resultados espacializados para a década de 2000 no Brasil e regiões
}

Bernardo Alves Furtado

\section{Introdução e literatura}

A percepção corrente é a de que o Brasil se modificou substancialmente e estruturalmente ao longo dos anos $2000 \mathrm{em}$ vários aspectos ${ }^{1}$. De fato, os dados do Censo 2010 comprovam essa percepção de mudança e confirmam a melhoria média da qualidade de vida dos cidadãos em dimensões variadas.

Entretanto, essa redução da vulnerabilidade das famílias ocorre de forma heterogênea e desigual entre as dimensões de análise e, especialmente, entre as regiões do País, seus Estados, seus Municípios e, até, entre porções do território municipal.

Essa riqueza de descrição das alterações sociais no período só é possível porque os dados fornecidos decenalmente pelos censos permitem a identificação espacial em grande escala, com resultados construídos a partir do âmbito familiar. Assim, o censo permite que se estimem indicadores temáticos, espacialmente detalhados, baseados nas respostas aos microdados da amostra. 
O presente texto - baseado na literatura teórica e metodológica recente (BARROS, Foguel e Ulyssea, 2007; SOARes, 2008, 2009) e com intuito precípuo de atualização dos dados com as novas informações disponíveis - objetiva contribuir com a leitura imediata, por parte de gestores públicos, pesquisadores e o público em geral, das informações subjacentes às respostas a centenas de perguntas feitas a milhares de famílias nos anos de 2000 e $2010^{2}$. Concentra-se, portanto, este texto, na descrição da construção dos indicadores e na análise dos resultados das referidas pesquisas do Censo.

Índices que buscam descrever a qualidade de vida das famílias ou, de forma oposta, a vulnerabilidade familiar, são comumente multidimensionais, de forma que não apenas a renda é vista como determinante das condições de vida, mas também o são a habitação e o acesso à urbanidade, ao trabalho, ao conhecimento, enfim, às oportunidades. Esse tipo de opção de mensuração pode se enquadrar no que Soares define, sob a ótica da pobreza, como a "falta de oportunidades para viver uma vida plena" (SOARES, 2009, p.13). De todo modo, índices de qualidade de vida multidimensionais se restringem à disponibilidade de dados presentes nas pesquisas domiciliares de larga cobertura.

De fato, pesquisadores costumam concordar que a vulnerabilidade das famílias é fenômeno que circunscreve a família de forma ampla e pode restringir seu acesso a oportunidades de maneiras diversas, seja pela qualidade inadequada da habitação em si ou pela sua precária localização, seja pela falta de acesso à educação e ao conhecimento, seja pelos efeitos dessa falta de conhecimento na prevenção e profilaxia da saúde, por exemplo.

Parece haver divergência, contudo, entre as formas utilizadas de se agregar as “dimensões da pobreza para a obtenção de uma medida escalar" (Barros; Carvalho; Franco, 2006). Alguns autores defendem que, no âmbito do combate à pobreza, por meio de políticas públicas, fazem-se necessários critérios objetivos, mensuráveis, não passíveis de dúvidas e que, nesse caso, a renda líquida é o critério mais adequado para seleção das famílias eleitas como alvo da política em questão (Osorio; SOARES; SouZA, 2011) ${ }^{3}$.

Se a ênfase do estudo, contudo, for a de sintetizar informações, permitir o ordenamento e a comparação entre regiões distintas e aspectos de necessidades diferentes, então índices escalares, multidimensionais, podem também ser de utilidade pública.

De fato, no âmbito das Nações Unidas, tendo em vista a comparabilidade entre países, a construção de índices de vulnerabilidade em geral se remete ao Relatório de Desenvolvimento Humano de 1996 e anos seguintes. No Brasil, também há alguma produção de indicadores, inclusive na escala intraurbana e intrametropolitana (Nahas, 2002; Rocha; Villela, 1990) e, no âmbito municipal, com intensa utilização de dados (QueIroz; Golgher, 2008).

O procedimento mínimo de construção de índices envolve a escolha de variáveis que retratem fenômenos de interesse e sua operacionalização, ou seja, a forma como se atribuirão valores a situações observadas e como essas informações serão tomadas no seu conjunto. Essa operação, de construção de partes do índice e de escolhas de composição aditiva do índice, é central, porque é dessa construção que derivam as possíveis observações que, em última análise, retratam o fenômeno que originariamente se buscava descrever. Decorre desse processo, portanto, que a construção do índice não é única; 
não é inequívoca e, assim, permite apenas interpretações de indícios fenomenológicos, condicionais ao desenho específico do índice construído.

Ainda assim, a despeito das diferenças nos procedimentos de construção de índices, pode se depreender que, observado o desenho de construção do índice, informações específicas para determinada faceta de ação pública são explicitadas para o agente público.

Finalmente, vale esclarecer que, no contexto utilizado neste texto, vulnerabilidade é o conceito associado à incapacidade da família de responder adequadamente, em tempo hábil, a eventos inesperados de ordem social ou ambiental ${ }^{4}$ (SÁnchez; Bertolozzi, 2007). Esta é a definição utilizada oficialmente no Brasil para a caracterização da Defesa Civil e de suas ações. "A intensidade de um desastre depende da interação entre a magnitude do evento adverso e a vulnerabilidade do sistema"(CAstro, A. L. C., 1999, p. 2). A vulnerabilidade do sistema está intrinsecamente ligada a questões específicas do local - sua geologia, sua infraestrutura, sua inclinação, por exemplo -, mas também da organização socioeconômica dos residentes as instituições, os laços sociais e familiares, o grau de preparo e antecipação de situações possíveis.

Essa vulnerabilidade se refere a questões físicas, tais como inundações, por exemplo, mas também a questões sociais e econômicas, tais como a perda de emprego e renda pelos adultos da família, doença do responsável ou inadequações temporárias da residência.

A título de exemplo, note que a capacidade econômica permite que, em caso de necessidades, a família tenha recursos para tomar as providências de bem estar imediatas à situação de risco que se coloca.
Recursos monetários facilitam ainda a tomada de decisão em relação a ações preventivas e recuperativas.

Dado o contexto e objetivos do texto, a ênfase que aqui se dá é na descrição metodológica, suas alterações e caracterização empírica das famílias a partir dos dados. Assim, dialoga-se com Barros, Carvalho e Franco (2006), além de outras referências para a discussão da literatura mais aprofundada.

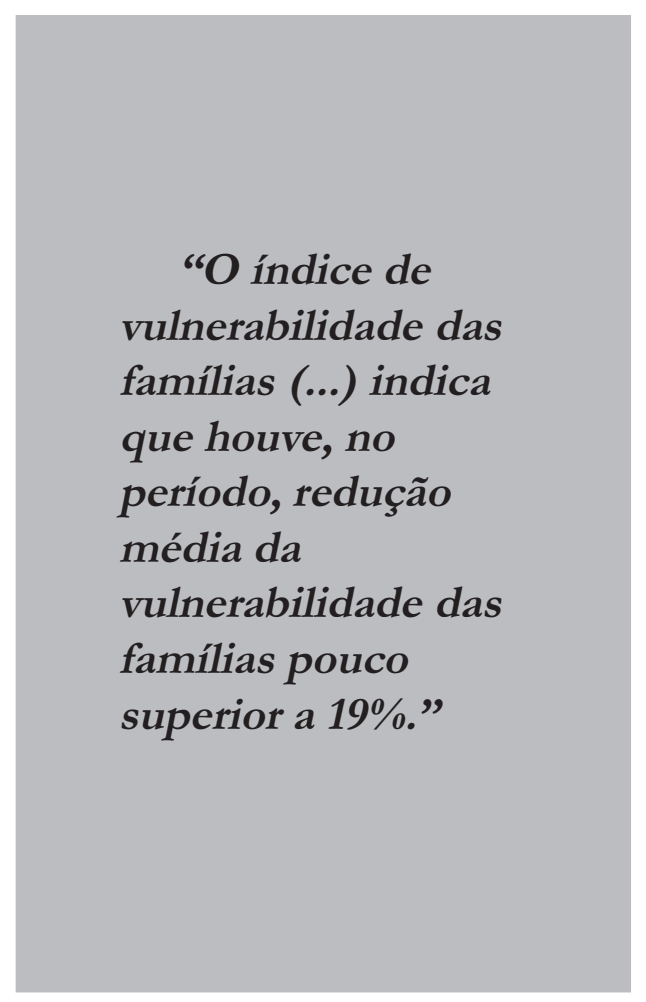

Sinteticamente, além desta introdução, o texto descreve a metodologia e os procedimentos para a construção do índice de vulnerabilidade baseado nas dimensões de (i) vulnerabilidade social; (ii) acesso ao conhecimento; (iii) acesso ao trabalho; (iv) escassez de recursos; (v) desenvolvimento infanto-juvenil e (vi) condições habitacionais. Essas dimensões - modificadas e 
adaptadas do trabalho original - contemplam um conjunto de 48 indicadores diferentes. Cada um deles, ou sua síntese, o índice final, podem ser expressos para os recortes geográficos de áreas de ponderação, internas aos municípios, até à síntese global nacional.

\section{Metodologia e procedimentos}

Os indicadores e a metodologia apresentados nesta seção buscam repetir a análise feita para a Pesquisa Nacional por Amostra de Domicílios (PNAD) em anos anteriores (BArros; Foguel; Ulyssea, 2007) naqueles quesitos cujas respostas eram suficientes para a construção do indicador. Em alguns casos, foram necessários ajustes ou troca de indicadores, conforme se descreve a seguir.

De acordo com a metodologia descrita por Barros, Carvalho e Franco (2006), procedemos ao cálculo de um "índice linear", calculado individualmente, para cada família (domicílio), de acordo com os microdados disponíveis. Como mencionado na introdução, são seis as dimensões analisadas, com o total de 48 indicadores.

Nos textos-base anteriores (BARros, Carvalho e Franco, 2006), apenas estão disponíveis critérios gerais acerca das decisões de construção dos indicadores. Nesse trabalho, detalhamos, nas tabelas que seguem (Tabelas 1 a 6 ), especificamente os critérios utilizados na interpretação do indicador, bem como as variáveis do Censo utilizadas para o cálculo para os anos de 2010 e 2000.

A construção do índice, como descrito originariamente por Barros, Foguel e Ulyssea (2007), se baseia em série de indicadores limiares de mensuração de vulnerabilidades para as quais se calcula a ocorrência ou ausência de aspecto específico.
Famílias abaixo do limiar para cada indicador recebem valores de 1. Caso contrário, o valor é zero. As dimensões e o índice final são calculados de acordo com a agregação descrita mais abaixo. Esta seção metodológica contém a descrição de cada um dos indicadores de cada dimensão e a forma como a agregação foi feita.

A vulnerabilidade social é a dimensão que busca quantificar a vulnerabilidade da família no seu aspecto mais geral (Tabela 1). A Tabela 1 apresenta os critérios de vulnerabilidade da família. A preocupação principal é retratar a capacidade da família de prover sua sustentabilidade, tanto financeira quanto de forma mais ampla, já que considera como parâmetros centrais a presença de bebês, crianças e idosos, cônjuges e sua proporção em relação ao número de dependentes no âmbito da família. Além disso, fatores como a ausência de cônjuge ou presença de criança que não viva com a mãe também impactam negativamente essa dimensão. Mais do que objeto de política pública, os resultados dessa dimensão retratam a evolução e composição dos membros familiares e sua capacidade de reprodução. Ainda assim, para o gestor público, o conhecimento da presença de famílias mais vulneráveis é relevante para a tomada de decisão da ação pública.

A dimensão acesso ao conhecimento (Tabela 2) quantifica, de um lado, a presença de adultos analfabetos ou baixa escolaridade e, de outro lado, a ausência de adultos com maior escolaridade ou exercendo funções profissionais de maior qualificação.

A dimensão acesso ao trabalho (Tabela 3) busca identificar simultaneamente o acesso ao trabalho proporcionalmente no âmbito familiar, bem como avaliar a qualidade (e formalidade) da ocupação, por meio 
do tipo de ocupação e dos rendimentos auferidos individualmente.

A escassez de recursos (Tabela 4) é caracterizada especificamente para aquelas famílias cuja renda domiciliar per capita é ou inferior à linha de pobreza ou extrema pobreza $(\mathrm{R} \$ 127,50)$ ou se é possível verificar dependência familiar em relação a programas de transferência de renda.
Os indicadores da dimensão desenvolvimento infanto-juvenil mensuram crianças e adolescentes que trabalham em consonância com aqueles que estão fora da escola ou fora do padrão de regularidade desejável (Tabela 5). Além disso, inclui na ponderação elementos de presença de óbito na família como fator relevante na estruturação do ambiente de convivência familiar.

\section{Tabela 1: Indicadores da componente vulnerabilidade social}

\begin{tabular}{|c|c|c|c|}
\hline Indicadores da componente & & Censo 2000 & Censo 2010 \\
\hline Vulnerabilidade social & Critérios & \multicolumn{2}{|c|}{ Variáveis } \\
\hline $\begin{array}{l}\text { V1. Alguma mulher teve filho } \\
\text { nascido vivo no último ano }\end{array}$ & $\begin{array}{l}\text { Existência de filho nascido } \\
\text { vivo no período de referência } \\
\text { de } 12 \text { meses anteriores }\end{array}$ & v4654 & v6664 \\
\hline $\begin{array}{l}\text { V2. Alguma mulher teve filho } \\
\text { nascido vivo nos últimos dois } \\
\text { anos }\end{array}$ & $\begin{array}{l}\text { Idade do último filho tido } \\
\text { nascido vivo }\end{array}$ & $\mathrm{v} 4654$ & v6660 \\
\hline V3. Presença de criança & $\begin{array}{l}\text { Considerada criança com } 12 \\
\text { anos ou menos idade }\end{array}$ & v4752 & v6036 \\
\hline $\begin{array}{l}\text { V4. Presença de criança ou } \\
\text { adolescente }\end{array}$ & $\begin{array}{l}\text { Considerado adolescente } \\
\text { com } 17 \text { anos ou menos }\end{array}$ & $\mathrm{v} 4752$ & v6036 \\
\hline $\begin{array}{l}\text { V5. Presença de criança, } \\
\text { adolescente ou jovem }\end{array}$ & $\begin{array}{l}\text { Considerado jovens como } \\
\text { menores ou igual a } 21 \text { anos }\end{array}$ & $\mathrm{v} 4752$ & v6036 \\
\hline V6. Presença de idoso & $\begin{array}{l}\text { Considerado idosos como } \\
\text { maiores de } 64 \text { anos }\end{array}$ & v4752 & v6036 \\
\hline V7. Ausência de cônjuge & No domicílio, excluídos solteiros & V0436 & v0502 \\
\hline $\begin{array}{l}\text { V8. Menos da metade dos } \\
\text { membros encontram-se em } \\
\text { idade ativa }\end{array}$ & $\begin{array}{l}\text { Considerado pessoas idade } \\
\text { ativa com } 10 \text { anos ou acima } \\
\text { dividido pelo total no domi- } \\
\text { cílio (excluídos empregados } \\
\text { domésticos e familiares) é } \\
\text { menor que meio }\end{array}$ & $\begin{array}{l}\mathrm{v} 4752 \mathrm{v} 0402 \\
\mathrm{v} 7100\end{array}$ & v6036 v0502 \\
\hline $\begin{array}{l}\text { V9. Presença de pessoas com } \\
\text { dificuldade grande ou impossi- } \\
\text { bilidade de caminhar, enxergar, } \\
\text { ouvir ou com deficiência } \\
\text { mental permanente }\end{array}$ & & $\begin{array}{l}\text { v0410 v0411 } \\
\text { v0412 v0413 } \\
\text { v0414 }\end{array}$ & $\begin{array}{l}\text { v0614 v0615 } \\
\text { v0616 v0617 }\end{array}$ \\
\hline $\begin{array}{l}\text { V10. Presença de criança no } \\
\text { domicílio que não viva com a } \\
\text { mãe. }\end{array}$ & $\begin{array}{l}\text { Ausência de cônjuge e adulto } \\
\text { masculinho no domicílio }\end{array}$ & v0402 v0401 & v0502 v0601 \\
\hline
\end{tabular}

Fonte: Elaboração própria. 
Tabela 2: Indicadores da componente acesso conhecimento

\begin{tabular}{l|l|c|c}
\hline Indicadores da componente & & Censo 2000 & Censo 2010 \\
\hline Acesso ao conhecimento & Critérios & \multicolumn{2}{|c}{ Variáveis } \\
\hline $\begin{array}{l}\text { C1. Presença de adulto anal- } \\
\text { fabeto }\end{array}$ & $\begin{array}{l}\text { Maior de 17 anos e 'não sabe } \\
\text { ler e escrever' }\end{array}$ & $\mathrm{v} 0428 \mathrm{v} 4752$ & v0627 v6036 \\
\hline $\begin{array}{l}\text { C2. Presença de adulto analfa- } \\
\text { beto funcional }\end{array}$ & $\begin{array}{l}\text { Maior de 17 anos e menos 7 } \\
\text { anos de estudo (fundamental } \\
\text { incompleto) }\end{array}$ & v4300 v4752 & v6400 v6036 \\
\hline $\begin{array}{l}\text { C3. Ausência de adulto com } \\
\text { fundamental completo }\end{array}$ & $\begin{array}{l}\text { Maior de 17 anos e fundamen- } \\
\text { tal completo }\end{array}$ & v4752 v4300 & v6036 v6400 \\
\hline $\begin{array}{l}\text { C4. Ausência de adulto com se- } \\
\text { cundário completo }\end{array}$ & $\begin{array}{l}\text { Considerado ensino médio } \\
\text { completo }\end{array}$ & v4752 v4300 & v6036 v6400 \\
\hline $\begin{array}{l}\text { C5. Ausência de adulto com } \\
\text { alguma educação superior }\end{array}$ & $\begin{array}{l}\text { Considerado acima de 11 anos } \\
\text { de estudo }\end{array}$ & v4752 v4300 & v6036 v6400 \\
\hline $\begin{array}{l}\text { C6. Ausência de trabalhador } \\
\text { com qualificação média ou alta }\end{array}$ & $\begin{array}{l}\text { Clasificações de ocupações } \\
\text { equivalentes a 1,2 e 3. Dirigen- } \\
\text { tes em geral, profissionais das } \\
\text { ciências e das artes e técnicos } \\
\text { de nível médio (excluídos ofi- } \\
\text { ciais forças armadas) }\end{array}$ & v4452 & v6461 \\
\hline
\end{tabular}

Fonte: Elaboração própria.

Tabela 3: Indicadores da componente acesso ao trabalho

\begin{tabular}{|c|c|c|c|}
\hline Indicadores da componente & & Censo 2000 & Censo 2010 \\
\hline Acesso ao trabalho & Critérios & \multicolumn{2}{|c|}{ Variáveis } \\
\hline $\begin{array}{l}\text { T1. Menos da metade dos mem- } \\
\text { bros em idade ativa encontram- } \\
\text { se ocupados }\end{array}$ & & v4452 & v6910 \\
\hline $\begin{array}{l}\text { T3. Ausência de ocupado no } \\
\text { setor formal }\end{array}$ & $\begin{array}{l}\text { Setor formal: Empregado com } \\
\text { carteira de trabalho assinada, } \\
\text { militar, funcionário público } \\
\text { estatutário, trabalhador domés- } \\
\text { tico com carteira de trabalho } \\
\text { assinada, exclui empregador e } \\
\text { empregado por conta própria }\end{array}$ & v0447 v0448 & v6930 \\
\hline $\begin{array}{l}\text { T4. Ausência de ocupado em } \\
\text { atividade não-agrícola }\end{array}$ & & v4462 & v6471 \\
\hline $\begin{array}{l}\text { T5. Ausência de ocupado com } \\
\text { rendimento superior a } 1 \text { salário } \\
\text { mínimo }\end{array}$ & $\begin{array}{l}\text { Salário Mínimo R\$ } 510 \text { (defla- } \\
\text { cionado IPCA } 2010 \text { para 2000, } \\
\text { valor equivalente a } R \$ 268,95\end{array}$ & v4525 & v6526 \\
\hline $\begin{array}{l}\text { T6. Ausência de ocupado com } \\
\text { rendimento superior a } 2 \text { salários } \\
\text { mínimos }\end{array}$ & $\begin{array}{l}\text { Salário Mínimo R\$ } 1.020 \\
\text { (deflacionado IPCA } 2010 \text { para } \\
2000 \text {, valor equivalente a } \\
\mathrm{R} \$ 537,89 \text { ) }\end{array}$ & $\mathrm{v} 4522$ & v6526 \\
\hline
\end{tabular}

Fonte: Elaboração própria. 
Tabela 4: Indicadores da componente escassez de recursos

\begin{tabular}{l|l|l|c}
\hline Indicadores da componente & & Censo 2000 & \multicolumn{1}{c}{ Censo 2010 } \\
\hline Escassez de recursos & Critérios & \multicolumn{2}{|c}{ Variáveis } \\
\hline $\begin{array}{l}\text { R1. Renda familiar per capita } \\
\text { inferior à linha de extrema } \\
\text { pobreza }\end{array}$ & $\begin{array}{l}\text { Considerada como sendo 1/4 do } \\
\text { salário mínimo, i.e., R\$ 127,50 } \\
\text { (para 2000 R\$ 67,24) }\end{array}$ & v4525 v4614 & v6525 v6527 \\
\hline $\begin{array}{l}\text { R2. Renda familiar per capita } \\
\text { inferior à linha de pobreza }\end{array}$ & $\begin{array}{l}\text { Considerada como sendo 1/2 do } \\
\text { salário mínimo, i.e., R\$255 (para } \\
2000 ~ R \$ 134,48)\end{array}$ & v4525 v4614 & v6525 v6527 \\
\hline $\begin{array}{l}\text { R3. Maior parte da renda fami- } \\
\text { liar advém de transferências }\end{array}$ & $\begin{array}{l}\text { Renda total menos renda traba- } \\
\text { lho maior que renda trabalho }\end{array}$ & v4525 v4614 & v6525 v6527 \\
\hline
\end{tabular}

Fonte: Elaboração própria.

Tabela 5: Indicadores da componente desenvolvimento infanto-juvenil

\begin{tabular}{|c|c|c|c|}
\hline Indicadores da componente & & Censo 2000 & Censo 2010 \\
\hline Desenvolvimento infanto-juvenil & Critérios & \multicolumn{2}{|c|}{ Variáveis } \\
\hline $\begin{array}{l}\text { D1. Presença de ao menos uma } \\
\text { criança com menos de } 14 \text { anos } \\
\text { trabalhando }\end{array}$ & & v4752 v0439 & v6036 v6900 \\
\hline $\begin{array}{l}\text { D2. Presença de ao menos uma } \\
\text { criança com menos de } 16 \text { anos } \\
\text { trabalhando }\end{array}$ & & v4752 v0439 & v6036 v6900 \\
\hline $\begin{array}{l}\text { D3. Presença de ao menos uma } \\
\text { criança de } 0-6 \text { anos fora da escola }\end{array}$ & & v4752 v0429 & v6036 v0628 \\
\hline $\begin{array}{l}\text { D4. Presença de ao menos uma } \\
\text { criança de } 7-14 \text { anos fora da escola }\end{array}$ & & v4752 v0429 & v6036 v0628 \\
\hline $\begin{array}{l}\text { D5. Presença de ao menos uma crian- } \\
\text { ça de } 7-17 \text { anos fora da escola }\end{array}$ & & v4752 v0429 & v6036 v0628 \\
\hline $\begin{array}{l}\text { D6. Presença de ao menos uma } \\
\text { criança de até } 14 \text { anos com mais de } \\
2 \text { anos de atraso }\end{array}$ & & v4752 v0431 & v6036 v0629 \\
\hline $\begin{array}{l}\text { D7. Presença de ao menos um ado- } \\
\text { lescente de } 10 \text { a } 14 \text { anos analfabeto }\end{array}$ & & v4752 v0528 & v6036 v0627 \\
\hline $\begin{array}{l}\text { D8. Presença de ao menos um jovem } \\
\text { de } 15 \text { a } 17 \text { anos analfabeto }\end{array}$ & & v4752 v0528 & $\mathrm{v} 6036 \mathrm{v} 0627$ \\
\hline $\begin{array}{l}\text { D9. Presença de ao menos uma mãe } \\
\text { que tenha algum filho que já tenha } \\
\text { morrido }\end{array}$ & $\begin{array}{l}\text { Considerado filhos e filhas (filhos } \\
\text { nascidos vivos maior filhos ainda } \\
\text { vivos) }\end{array}$ & v4620 v0463 & v6036 v0663 \\
\hline $\begin{array}{l}\text { D10. Presença de mais de uma mãe } \\
\text { que tenha algum filho que já tenha } \\
\text { morrido }\end{array}$ & & v4620 v0463 & v6036 v0663 \\
\hline $\begin{array}{l}\text { D11. Presença de mãe que já teve } \\
\text { algum filho nascido morto }\end{array}$ & & v4670 & v0669 \\
\hline
\end{tabular}

Fonte: Elaboração própria. 
Os indicadores que compõem a dimensão de condições habitacionais (Tabela 6) buscam refletir de forma mais abrangente a moradia como instrumento de inserção social e elemento de suporte contra a vulnerabilidade. Nesse sentido, a condição de domicílio próprio, por exemplo, reforça o fato de que, em evento de desocupação laboral dos adultos do domicílio, não há necessidade imediata de arcar com custos de aluguel da habitação. Outros componentes referem-se à qualidade intrínseca da habitação e à disponibilidade de instrumentos mínimos de acesso a serviços. Finalmente, buscou-se incluir na vulnera- bilidade da habitação elementos de localização espacial que são quantificados pela necessidade de membros do domićlilo de se locomoverem a outro município para efeitos de acesso à educação ou ao trabalho.

\section{Agregação de indicadores}

Os indicadores de cada dimensão precisam ser agregados para, na sequência, comporem o índice nacional. A agregação escolhida segue a orientação teórica de construção dos indicadores. Ou seja, agrega-se de acordo com a escolha temática comum de grupo de indicadores e relevância para a vulnerabilidade, de acordo

\section{Tabela 6: Indicadores da componente de condições habitacionais}

\begin{tabular}{|c|c|c|c|}
\hline Indicadores da componente & & Censo 2000 & Censo 2010 \\
\hline Condições habitacionais & Critérios & \multicolumn{2}{|c|}{ Variáveis } \\
\hline H1. Domicílio não é próprio & Pago ou "pagando" & v0205 & v0201 \\
\hline $\begin{array}{l}\text { H2. Domicílio não é nem próprio } \\
\text { nem cedido }\end{array}$ & É alugado ou outra condição & v0205 & v0201 \\
\hline $\begin{array}{l}\text { H3. Densidade de } 2 \text { ou mais mo- } \\
\text { radores por dormitório }\end{array}$ & Maior ou igual & v7203 & v6203 \\
\hline H5. Acesso inadequado à água & $\begin{array}{l}\text { Considerado não tem água canali- } \\
\text { zada em pelo menos um cômodo }\end{array}$ & v0208 & v0208 \\
\hline $\begin{array}{l}\text { H6. Esgotamento sanitário inade- } \\
\text { quado }\end{array}$ & $\begin{array}{l}\text { Considerado fossa rudimentar, vala, } \\
\text { direto rio ou lago, outra forma }\end{array}$ & v0211 & v0207 \\
\hline H7. Lixo não é coletado & Nem direta, nem indiretamente & v0212 & $\mathrm{v} 0210$ \\
\hline H8. Sem acesso à eletricidade & Considerada somente elétrica & v0213 & v0211 \\
\hline H9. Não tem geladeira & & v0215 & v0216 \\
\hline $\begin{array}{l}\text { H10. Não tem ao menos um dos } \\
\text { itens: geladeira, televisão ou rádio }\end{array}$ & & $\begin{array}{l}\mathrm{v} 0215 \mathrm{v} 0214 \\
\mathrm{v} 0221\end{array}$ & $\begin{array}{l}\text { v0213 v0214 } \\
\text { v0216 }\end{array}$ \\
\hline $\begin{array}{l}\text { H11. Não tem ao menos um dos } \\
\text { itens: geladeira, televisão, rádio ou } \\
\text { telefone }\end{array}$ & Considerada telefone fixo & $\begin{array}{l}\text { v0215 v0214 } \\
\text { v0221 v0219 }\end{array}$ & $\begin{array}{l}\mathrm{v} 0212 \mathrm{v} 0214 \\
\mathrm{v} 0216 \mathrm{v} 0218\end{array}$ \\
\hline $\begin{array}{l}\text { H12. Não tem ao menos um dos } \\
\text { itens: geladeira, televisão, rádio, } \\
\text { telefone ou computador }\end{array}$ & & $\begin{array}{ll}\mathrm{v} 0215 & \mathrm{v} 0214 \\
\mathrm{v} 0221 & \mathrm{v} 0219 \\
\mathrm{v} 0220\end{array}$ & $\begin{array}{l}\mathrm{v} 0213 \mathrm{v} 0214 \\
\mathrm{v} 0216 \mathrm{v} 0218 \\
\mathrm{v} 0219\end{array}$ \\
\hline $\begin{array}{l}\text { H13. Mobilidade. Trabalha ou } \\
\text { estuda em município diferente da } \\
\text { residência }\end{array}$ & & v4276 & v0660 v0636 \\
\hline H14. Domicílio improvisado & & v0201 & v4001 \\
\hline
\end{tabular}

Fonte: Elaboração própria. 
com a estrutura proposta originalmente por Barros, Foguel e Ulyssea (2007). Pode-se questionar se a escolha da agregação de indicadores e a junção de cada dimensão com contribuições iguais à composição total do índice seriam adequadas. Nesse caso, a título de teste e validação, realizamos alguns exercícios de análise fatorial, cuja metodologia delega ao conjunto de dados e suas relações internas as possibilidades de agregação em fatores (ou componentes). Feitos os cálculos, a composição das dimensões se deu de forma similar à adição por quantidades iguais. Observar-se-iam algumas inversões de algumas unidades $\mathrm{da}$ Federação (UF) no seu ranqueamento, porém, com alterações pouco significativas no nível absoluto do índice final. No caso dos indicadores individuais, observe-se que a agregação interna a cada dimensão é feita observando-se a consistência teórica de cada tema. Assim, optou-se pela agregação teoricamente informada.

De todo modo, a intenção de agregar informações em dimensões e no índice síntese cumpre apenas o papel de facilitar o entendimento dos dados. Cada indicador, de forma individual, também pode ser objeto de análise, como demonstram as análises das Tabelas 9 e 10.
Especificamente, em relação à agregação para o caso da vulnerabilidade social, por exemplo (Tabela 7), tira-se a média dos indicadores v1 e v2, soma-se a média dos indicadores v3, v4 e v5, soma-se v6, a média de v7 e v8, soma-se ainda v9 e v10 e tira-se a média geral, dividindo-se por 6 . As outras dimensões são agregadas de acordo com o exposto na Tabela 7 .

O índice geral é formado a partir da média simples das seis dimensões.

\section{Recortes geográficos possíveis}

O censo demográfico realizado decenalmente pelo IBGE é a ferramenta que permite o melhor desenho espacial amostral no âmbito das pesquisas domiciliares brasileiras. Diferentemente da anualmente realizada, a PNAD, cuja amostra permite análise de regiões metropolitanas e unidades da Federação, os microdados da amostra do Censo permitem análise por áreas de ponderação, que é a "unidade geográfica, formada por um agrupamento de setores censitários, para a aplicação dos procedimentos de calibração das estimativas com as informações conhecidas para a população como um todo" (IBGE, 2010, p. 45). Ao todo, há informações diferenciadas por 10.184 diferentes áreas de ponderação, com mais

Tabela 7: Forma de agregação de indicadores em dimensões

\begin{tabular}{|c|c|c|c|c|c|c|c|c|c|}
\hline Dimensāo & Agre & gação dos in & dicadores po & or média & $\operatorname{sim}$ & les d & cada grupo & & \\
\hline Vulnerabilidade social & $v 1+v_{2}$ & $\begin{array}{c}\sqrt{3}+v 4+ \\
v 5\end{array}$ & v6 & $y^{7}+v^{2}$ & (9) & v10 & & & \\
\hline Acesso ao conhecimento & $c 1+c 2$ & $c 3+c 4+c 5$ & 66 & & & & & & \\
\hline Acesso ao trabalho & $\mathrm{tI}$ & $t 3+t 4$ & $15+t 6$ & & & & & & \\
\hline Escássez de recursos & $\mathrm{rl}$ & +2 & $\mathrm{r} 3$ & & & & & & \\
\hline $\begin{array}{l}\text { Desenvolvimento infanto- } \\
\text { juvenil }\end{array}$ & $\mathrm{d} 1+\mathrm{d} 2$ & $\begin{array}{c}\mathrm{d} 3+\mathrm{d} 4+ \\
\mathrm{d} 5\end{array}$ & $\begin{array}{c}d 6+d 7+d 8 \\
+d 9+d 10+ \\
d 11\end{array}$ & & & & & & \\
\hline Condiçôes habitacionais & $h_{1}+h_{2}$ & h3 3 & h5 & hG & h7 7 & h8 & $\begin{array}{l}\mathrm{h} 9+\mathrm{h} 10+ \\
\mathrm{h} 11+\mathrm{h} 12\end{array}$ & h13 & h14 \\
\hline
\end{tabular}

Fonte: Elaboração própria. 
de mil Municípios com mais de uma área de ponderação.

\section{Resultados}

O índice de vulnerabilidade das famílias - construído de acordo com as premissas observadas acima e a partir dos microdados da amostra dos censos demográficos de 2000 e 2010 realizados pelo IBGE - indica que houve, no período, redução média da vulnerabilidade das famílias pouco superior a 19\% (Tabela 8).

A redução foi influenciada diferentemente pelas várias dimensões. Central para a redução foi o aumento do acesso da população ao trabalho e aos recursos financeiros, reduzindo em cerca de $29 \%$ e $36 \%$ respectivamente tais indicadores. $\mathrm{O}$ desenvolvimento infanto-juvenil apresentou redução no índice da ordem de $16,5 \%$. Finalmente, as dimensões com pior desempenho foram as condições habitacionais $(14 \%)$, o acesso ao conhecimento - ainda com patamares altos em valores absolutos $^{5}$ - e a vulnerabilidade social. A análise das alterações por indicadores de cada uma dessas dimensões permite antever indícios das razões destas alterações diferenciadas.

De fato, a análise da Tabela 9 indica que somente a dimensão de acesso ao conhecimento obteve redução em todos os indicadores componentes. Ainda assim, os indicadores c5 e c6 (ausência de adulto com alguma educação superior e ausência de trabalhador com qualificação média ou alta) reduziram-se em ritmo lento, apenas 2,5\% e 3,1\% de melhora na década.

Em relação à dimensão de vulnerabilidade social, note que há aumento da vulnerabilidade devido a maior presença de idosos, bem como maior número de domicílios com ausência de cônjuge (v6 e v7). Além disso, há aumento do número de residências nas quais há indivíduos com algum tipo de deficiência, provavelmente por melhorias na notificação dos casos de deficiência. Finalmente, há quase estabilidade (aumento de 0,001 ) no indicador referente a crianças que moram em domicílios sem a presença da mãe.

Os indicadores de acesso ao trabalho confirmam a evolução da inserção no mercado de ocupação formal na década. De forma significativa, note a redução em

Tabela 8: Resultados da média índice geral e suas dimensões Brasil

\begin{tabular}{l|c|c|c}
\hline & $\mathbf{2 0 0 0}$ & $\mathbf{2 0 1 0}$ & $\mathbf{2 0 1 0 - 2 0 0 0 ( \% )}$ \\
\hline Índice Brasil (média) & 0,305 & 0,246 & $-19,3 \%$ \\
\hline Vulnerabilidade social & 0,206 & 0,187 & $-9,2 \%$ \\
\hline Acesso ao conhecimento & 0,645 & 0,568 & $-11,9 \%$ \\
\hline Acesso ao trabalho & 0,466 & 0,329 & $-29,4 \%$ \\
\hline Escassez de recursos & 0,218 & 0,139 & $-36,2 \%$ \\
\hline Desenvolvimento infanto-juvenil & 0,133 & 0,111 & $-16,5 \%$ \\
\hline Condições habitacionais & 0,162 & 0,140 & $-13,6 \%$
\end{tabular}

Fonte: Elaboração própria. Informações extraídas dos microdados da amostra dos censos demográficos IBGE 2000 e 2010. 
nível do indicador $\mathrm{t} 1$ - maioria dos adultos desocupados - que passa de 0,392 a 0,032, com consequente redução de mais de $90 \%$ no indicador. Além da quantidade de desocupados por domicílio se reduzir, também melhoraram aspectos relacionados à formalidade da ocupação (t3) e da remuneração percebida (t5 e t6). Ainda assim, mais domicílios apresentaram no período ocupações exclusivamente agrícolas ( $\mathrm{t} 4$ ).

A dimensão de acesso a recursos contribui de forma importante para a redução geral da vulnerabilidade das famílias. Todavia, a decomposição da dimensão em seus componentes revela que, embora os indicadores referentes ao número de domicílios com renda per capita abaixo da linha de pobreza e extrema pobreza se reduza em cerca de $40 \%$, o indicador referente à dependência dessas famílias de transferências governamentais aumenta em quase $800 \%$. Aliás, já foi demonstrado em outros textos (SOARES, 2008) que a transferência direta (r3) é fundamental para retirar as pessoas da pobreza (r1 e r2). De todo modo, a dimensão não falha em capturar ambos os fenômenos de aumento da dependência e redução de famílias abaixo das linhas.

A dimensão de desenvolvimento infanto-juvenil apresenta componentes díspares (Tabela 10). Se, de um lado, há aumento da vulnerabilidade dado o maior número de crianças e adolescentes que trabalham em média, de outro lado, a presença de mães com filhos que tenham

Tabela 9: Resultados para indicadores das dimensões vulnerabilidade social, acesso ao conhecimento e ao trabalho e escassez de recursos

\begin{tabular}{c|c|c|c}
\hline Indicador & Média BR 2000 & Média BR 2010 & $\mathbf{2 0 1 0}-\mathbf{2 0 0 0} \mathbf{( \% )}$ \\
\hline v1 & 0,159 & 0,050 & $-68,6 \%$ \\
\hline v2 & 0,222 & 0,162 & $-27,0 \%$ \\
\hline v3 & 0,527 & 0,421 & $-20,1 \%$ \\
\hline v4 & 0,645 & 0,534 & $-17,2 \%$ \\
\hline v5 & 0,719 & 0,612 & $-14,9 \%$ \\
\hline v6 & 0,174 & 0,192 & $10,3 \%$ \\
\hline v7 & 0,220 & 0,222 & $0,9 \%$ \\
\hline v8 & 0,039 & 0,028 & $-28,2 \%$ \\
\hline v9 & 0,129 & 0,176 & $36,4 \%$ \\
\hline v10 & 0,010 & 0,011 & $-26,0 \%$ \\
\hline c1 & 0,238 & 0,174 & $-18,8 \%$ \\
\hline c2 & 0,751 & 0,610 & $-30,4 \%$ \\
\hline c3 & 0,451 & 0,314 & $-23,1 \%$ \\
\hline c4 & 0,631 & 0,485 & $-2,5 \%$ \\
\hline c5 & 0,855 & 0,834 & $-3,1 \%$ \\
\hline c6 & 0,794 & 0,769 & $-91,8 \%$ \\
\hline t1 & 0,392 & 0,032 & $-11,1 \%$ \\
\hline t3 & 0,549 & 0,488 & $5,1 \%$ \\
\hline t4 & 0,292 & 0,307 & $-8,1 \%$ \\
\hline t5 & 0,459 & 0,422 & $-2,7 \%$ \\
\hline t6 & 0,709 & 0,690 & $-44,6 \%$ \\
\hline r1 & 0,224 & 0,124 & $-39,5 \%$ \\
\hline r2 & 0,425 & 0,257 & $775,0 \%$ \\
\hline r3 & 0,004 & 0,035 & \\
\hline
\end{tabular}

Fonte: Elaboração própria. Informações extraídas de microdados da amostra dos censos demográficos IBGE 2000 e 2010. 
Tabela 10: Resultados para indicadores das dimensões desenvolvimento infanto-juvenil e condições habitacionais

\begin{tabular}{|c|c|c|c|}
\hline Indicador & 2000 & 2010 & $2010-2000(\%)$ \\
\hline d1 & 0,005 & 0,012 & $140,0 \%$ \\
\hline d2 & 0,019 & 0,028 & $47,4 \%$ \\
\hline d3 & 0,143 & 0,151 & $5,6 \%$ \\
\hline $\mathrm{d} 4$ & 0,371 & 0,309 & $-16,7 \%$ \\
\hline d5 & 0,443 & 0,378 & $-14,7 \%$ \\
\hline d6 & 0,114 & 0,104 & $-8,8 \%$ \\
\hline d7 & 0,019 & 0,009 & $-52,6 \%$ \\
\hline d8 & 0,009 & 0,003 & $-66,7 \%$ \\
\hline d9 & 0,155 & 0,003 & $-98,1 \%$ \\
\hline d10 & 0,004 & 0,000 & $-100,0 \%$ \\
\hline d11 & 0,113 & 0,083 & $-26,5 \%$ \\
\hline h1 & 0,250 & 0,265 & $6,0 \%$ \\
\hline h2 & 0,151 & 0,187 & $23,8 \%$ \\
\hline h3 & 0,047 & 0,023 & $-51,1 \%$ \\
\hline h5 & 0,168 & 0,093 & $-44,6 \%$ \\
\hline h6 & 0,320 & 0,310 & $-3,1 \%$ \\
\hline h7 & 0,209 & 0,126 & $-39,7 \%$ \\
\hline h8 & 0,055 & 0,013 & $-76,4 \%$ \\
\hline h9 & 0,166 & 0,063 & $-62,0^{\circ} \%$ \\
\hline h10 & 0,263 & 0,237 & $-9,9 \%$ \\
\hline h11 & 0,634 & 0,639 & $0,8 \%$ \\
\hline h12 & 0,905 & 0,759 & $-16,1 \%$ \\
\hline h13 & 0,137 & 0,197 & $43,8 \%$ \\
\hline h14 & 0,005 & 0,002 & $-60,0 \%$ \\
\hline
\end{tabular}

Fonte: Elaboração própria. Informações extraídas dos microdados da amostra dos censos demográficos IBGE 2000 e 2010.

morrido diminui fortemente. De maneira geral, também há melhora na presença de crianças e adolescentes nas escolas.

As condições habitacionais também evoluíram de forma heterogênea na década analisada. Os indicadores que refletem a não propriedade do imóvel (d1 e d2) - e, portanto, maior vulnerabilidade, por exemplo, na ocorrência de desocupação dos adultos do domicílio e incapacidade de arcar com o custo imediato do aluguel apresentaram aumento relevante. De outro lado, entretanto, condições de habitabilidade específicas, como acesso a água, 
esgoto e tratamento de lixo, melhoraram no período. Assim como também foram positivos os resultados referentes à posse de itens de conforto e comunicação no âmbito domiciliar. Se considerados aspectos ligados à localização da residência - e à necessidade de que os indivíduos precisem ir a outros Municípios para acesso à escola e ao trabalho - então houve piora significativa do indicador (43,8\%).

Como se vê, embora a redução da vulnerabilidade tenha ocorrido em todas as dimensões analisadas, há variação importante entre aspectos e magnitudes específicas dos indicadores de cada dimensão.

Da mesma forma, a análise regional demonstra variabilidade diferenciada entre as Grandes Regiões do IBGE, embora em menor magnitude (diferença de 3,7 p.p). O Sul é a região que apresenta queda mais significativa do índice geral, com redução de $22,1 \%$ de vulnerabilidade. Aproxima-se do patamar global da região Sudeste. O Norte é a região com menor evolução no período, aproximando-se do patamar da região Nordeste, com pior desempenho $(0,311)$.

Em relação à dicotomia urbano-rural de acordo com definições estabelecidas em lei municipal e incorporação do IBGE -, note que a redução percentual é maior nas áreas urbanas, entretanto, dado o nível inicial da vulnerabilidade rural ser mais alto, houve, de fato, redução na distância entre os indicadores no período, caindo de 0,155 pontos para 0,146 .

A análise do indicador agregado por regiões metropolitanas deve considerar que o IBGE utilizou a definição oficial estabelecida em leis estaduais - para regiões metropolitanas, que, na ocasião do Censo

Tabela 11: Resultados por região, urbano - rural e metropolitano - não-metropolitano

\begin{tabular}{l|c|c|c}
\hline & \multicolumn{2}{|c|}{ Índice } & $\mathbf{2 0 1 0 - 2 0 0 0} \mathbf{( \% )}$ \\
\hline Média Brasil & $\mathbf{2 0 0 0}$ & $\mathbf{2 0 1 0}$ & \\
\hline Norte & $\mathbf{0 , 3 0 5}$ & $\mathbf{0 , 2 4 6}$ & $-19,3 \%$ \\
\hline Nordeste & 0,370 & 0,302 & $-18,4 \%$ \\
\hline Sudeste & 0,388 & 0,311 & $-19,8 \%$ \\
\hline Sul & 0,263 & 0,212 & $-19,4 \%$ \\
\hline Centro-Oeste & 0,292 & 0,228 & $-21,9 \%$ \\
\hline & & & \\
\hline Urbano & 0,279 & 0,225 & $-19,4 \%$ \\
\hline Rural & 0,434 & 0,371 & $-14,5 \%$ \\
\hline & & & \\
\hline Metropolitano & 0,263 & 0,212 & $-19,2 \%$ \\
\hline Não-metropolitano & 0,344 & 0,276 & $-19,5 \%$ \\
\hline
\end{tabular}

Fonte: Elaboração própria. Informações extraídas dos microdados da amostra dos censos demográficos IBGE 2000 e 2010. 
2010, constavam como 36 regiões metropolitanas, três aglomerações urbanas e três $\mathrm{RIDE}^{6}$ - que integram Municípios em fronteiras estaduais. Não se entenda, portanto, 'metropolitano' como fenômeno ou processo imbuído de atividades de hierarquia superior, mas apenas como definição entendida pelos legisladores estaduais - usualmente utilizada como ferramenta de desenvolvimento regional. Todavia, o 'não-metropolitano' ainda apresenta assim como o rural - níveis do indicador de vulnerabilidade mais altos que áreas metropolitanas, embora com redução ligeiramente mais acentuada.

Como reforçado anteriormente, na medida em que se detalha a análise por regiões geográficas, dimensões e indicadores, o pesquisador pode observar heterogeneidades interessantes. A Tabela 12, por exemplo, permite inferir que o Norte foi a região que apresentou a pior evolução na dimensão infanto-juvenil (-12\%); que o Nordeste, por sua vez, teve desempenho abaixo da média brasileira nas dimensões de acesso ao trabalho (-26,2\%) e escassez de recursos $(-30,5 \%)$, mas melhores em desenvolvimento infanto-juvenil (-22\%) e condições habitacionais $(-20,7 \%)$. O Sudeste apresenta a pior evolução em redução da vulnerabilidade social $(-8,3 \%)$ e em condições habitacionais $(-7,3 \%)$. O Sul e o Centro-oeste alcançam redução de vulnerabilidade importante na dimensão de escassez de recursos, 54,5 e 50,3\%, respectivamente.

Mais uma vez em relação à dicotomia urbano-rural, note que, enquanto o melhor desempenho em áreas urbanas é em relação ao aumento de acesso ao trabalho (31,3\%), as áreas rurais apresentam melhorias significativas em relação à vulnerabilidade social $(10,3 \%)$ e às condições habitacionais $(18,8 \%)$.

Entre os resultados apresentados de forma segmentada entre regiões, urbano, rural e metropolitano e as dimensões, a variação mais baixa - de piora da vulnerabilidade - ocorreu em relação às condições habitacionais em áreas metropolitanas $(5,2 \%)$, embora ainda em níveis melhores do que a média brasileira.

Tabela 12: Resultados para as dimensões por regiões, urbano e rural e metropolitano, não-metropolitano

\begin{tabular}{|c|c|c|c|c|c|c|c|c|c|c|c|c|}
\hline & \multicolumn{2}{|c|}{$\begin{array}{l}\text { Vulnerabilidade } \\
\text { social }\end{array}$} & \multicolumn{2}{|c|}{$\begin{array}{c}\text { Acesso ao } \\
\text { conhecimento }\end{array}$} & \multicolumn{2}{|c|}{ Acesso ao trabalho } & \multicolumn{2}{|c|}{$\begin{array}{c}\text { Escassez de } \\
\text { recursos }\end{array}$} & \multicolumn{2}{|c|}{$\begin{array}{c}\text { Desenvolvimento } \\
\text { infanto-juvenil }\end{array}$} & \multicolumn{2}{|c|}{$\begin{array}{c}\text { Condições } \\
\text { habitacionais }\end{array}$} \\
\hline & 2000 & 2010 & 2000 & 2010 & 2000 & 2010 & 2000 & 2010 & 2000 & 2010 & 2000 & 2010 \\
\hline Média Brasil & 0,206 & 0,187 & 0,645 & 0,568 & 0,466 & 0,329 & 0,218 & 0,139 & 0,133 & 0,111 & 0,162 & 0,140 \\
\hline Norte & 0,239 & 0,214 & 0,695 & 0,608 & 0,519 & 0,382 & 0,323 & 0,231 & 0,166 & 0,146 & 0,276 & 0,229 \\
\hline Nordeste & 0,233 & 0,209 & 0,739 & 0,653 & 0,588 & 0,434 & 0,364 & 0,253 & 0,164 & 0,128 & 0,242 & 0,192 \\
\hline Sudeste & 0,193 & 0,177 & 0,597 & 0,526 & 0,413 & 0,283 & 0,148 & 0,089 & 0,117 & 0,099 & 0,109 & 0,101 \\
\hline Sul & 0,192 & 0,174 & 0,617 & 0,541 & 0,419 & 0,280 & 0,154 & 0,070 & 0,119 & 0,101 & 0,130 & 0,114 \\
\hline Centro-Oeste & 0,198 & 0,177 & 0,631 & 0,546 & 0,422 & 0,283 & 0,193 & 0,096 & 0,127 & 0,108 & 0,182 & 0,160 \\
\hline Urbano & 0,203 & 0,185 & 0,605 & 0,533 & 0,432 & 0,297 & 0,182 & 0,112 & 0,129 & 0,107 & 0,123 & 0,115 \\
\hline Rural & 0,224 & 0,201 & 0,842 & 0,782 & 0,635 & 0,52 & 0,396 & 0,301 & 0,154 & 0,134 & 0,356 & 0,289 \\
\hline Metropolitano & 0,197 & 0,180 & 0,573 & 0,502 & 0,405 & 0,275 & 0,161 & 0,101 & 0,122 & 0,103 & 0,116 & 0,110 \\
\hline $\begin{array}{l}\text { Não- } \\
\text { metropolitano }\end{array}$ & 0,215 & 0,194 & 0,71 & 0,629 & 0,521 & 0,378 & 0,27 & 0,173 & 0,143 & 0,118 & 0,204 & 0,167 \\
\hline
\end{tabular}

Fonte: Elaboração própria. Informações extraídas dos microdados da amostra dos censos demográficos IBGE 2000 e 2010. 
A análise das unidades da Federação revela que o estado que apresentou menor redução do indicador de vulnerabilidade foi Roraima (Tabela 13). Ressalte-se, todavia, que o estado do Maranhão, ainda que com redução do indicador próxima à média nacional, permanece como Estado com pior indicador de vulnerabilidade. A segunda e terceira colocações permanecem com Piauí e Alagoas. Em termos relativos, o Tocantins foi o Estado que conseguiu melhor desempenho no

Tabela 13: Resultados do índice por unidades da Federação

\begin{tabular}{|c|c|c|c|}
\hline & \multicolumn{2}{|c|}{ Índice } & \multirow[b]{2}{*}{$2010-2000(\%)$} \\
\hline & 2000 & 2010 & \\
\hline Brasil & 0,305 & 0,246 & $-19,3 \%$ \\
\hline Rondônia & 0,338 & 0,268 & $-20,7 \%$ \\
\hline Acre & 0,373 & 0,305 & $-18,2 \%$ \\
\hline Amazonas & 0,367 & 0,296 & $-19,3 \%$ \\
\hline Roraima & 0,320 & 0,279 & $-12,8 \%$ \\
\hline Pará & 0,383 & 0,320 & $-16,4 \%$ \\
\hline Amapá & 0,341 & 0,276 & $-19,1 \%$ \\
\hline Tocantins & 0,374 & 0,281 & $-24,9 \%$ \\
\hline Maranhão & 0,429 & 0,348 & $-18,9 \%$ \\
\hline Piauí & 0,409 & 0,331 & $-19,1 \%$ \\
\hline Ceará & 0,389 & 0,310 & $-20,3 \%$ \\
\hline Rio Grande do Norte & 0,371 & 0,291 & $-21,6 \%$ \\
\hline Paraíba & 0,386 & 0,312 & $-19,2 \%$ \\
\hline Pernambuco & 0,371 & 0,300 & $-19,1 \%$ \\
\hline Alagoas & 0,405 & 0,328 & $-19,0 \%$ \\
\hline Sergipe & 0,376 & 0,301 & $-19,9 \%$ \\
\hline Bahia & 0,381 & 0,303 & $-20,5 \%$ \\
\hline Minas Gerais & 0,302 & 0,237 & $-21,5 \%$ \\
\hline Espírito Santo & 0,297 & 0,233 & $-21,5 \%$ \\
\hline Rio de Janeiro & 0,259 & 0,211 & $-18,5 \%$ \\
\hline São Paulo & 0,244 & 0,200 & $-18,0 \%$ \\
\hline Paraná & 0,283 & 0,220 & $-22,3 \%$ \\
\hline Santa Catarina & 0,260 & 0,200 & $-23,1 \%$ \\
\hline Rio Grande do Sul & 0,268 & 0,215 & $-19,8 \%$ \\
\hline Mato Grosso do Sul & 0,305 & 0,237 & $-22,3 \%$ \\
\hline Mato Grosso & 0,311 & 0,245 & $-21,2 \%$ \\
\hline Goiás & 0,304 & 0,236 & $-22,4 \%$ \\
\hline Distrito Federal & 0,227 & 0,183 & $-19,4 \%$ \\
\hline
\end{tabular}

Fonte: Elaboração própria. Informações extraídas microdados da amostra dos censos demográficos IBGE 2000 e 2010. 
período, reduzindo seu indicador do nível alto para mais próximo da média nacional. Estados do Sul, Sudeste e Centro-oeste apresentaram boa redução, acima dos $20 \%$, e aprofundaram sua distância em relação à média nacional. A unidade da Federação com menor vulnerabilidade permanece o Distrito Federal $(0,183)$.

Novamente, advoga-se que informações adicionais podem ser obtidas ao desagregar as dimensões analisadas no âmbito das unidades da Federação (Tabela 14). Os Estados do Nordeste, em especial, tiveram reduções bem acima da média (da ordem de 6 ou mais p.p.) na dimensão de desenvolvimento infanto-juvenil. A Bahia e o Tocantins apresentaram as melhores reduções nas condições habitacionais $(-25 \%$ e $-26,3 \%)$. Os Estados do Sul e Centro-oeste, por sua vez, apresentaram números de melhoria no acesso a recursos cerca de 20 pontos percentuais em relação à média nacional.

Alguns aspectos negativos merecem realce. O Amazonas reduziu seu índice de vulnerabilidade na dimensão de desenvolvimento infanto-juvenil em apenas 4,85\%. Os dois Estados seguintes com piores resultados são Acre (5,73\%) e Amapá $(7,02)$. Roraima, por sua vez, apresenta destaque negativo nas dimensões acesso ao trabalho $(-18,39 \%)$ e escassez de recursos $(-17 \%)$.

$\mathrm{Na}$ dimensão de condições habitacionais, apenas dois Estados tiveram piora do indicador no período analisado: São Paulo, com piora de 1,09\% no período, e o Distrito Federal, com aumento da vulnerabilidade nessa dimensão de quase $20 \%$. Ainda assim, ressalte-se que ambas as unidades da Federação apresentam valores abaixo da média nacional de 0,14 em 2010 $(0,093$ e 0,104 , respectivamente).

Tabela 14: Resultados por unidades da Federação e dimensões

\begin{tabular}{|c|c|c|c|c|c|c|c|c|c|c|c|c|}
\hline & 2000 & 2010 & 2000 & 2010 & 2000 & 2010 & 2000 & 2010 & 2000 & 2010 & 2000 & 2010 \\
\hline & \multicolumn{2}{|c|}{ Vulnerabilidade } & \multicolumn{2}{|c|}{ Conhecimento } & \multicolumn{2}{|c|}{ Trabalho } & \multicolumn{2}{|c|}{ Recursos } & \multicolumn{2}{|c|}{ Infanto-juvenil } & \multicolumn{2}{|c|}{ Habitação } \\
\hline Média Brasil & 0,206 & 0,187 & 0,645 & 0,568 & 0,466 & 0,329 & 0,218 & 0,139 & 0,133 & 0,111 & 0,162 & 0,140 \\
\hline Rondônia & 0,210 & 0,184 & 0,699 & 0,609 & 0,467 & 0,334 & 0,249 & 0,145 & 0,142 & 0,122 & 0,260 & 0,215 \\
\hline Acre & 0,246 & 0,220 & 0,714 & 0,624 & 0,518 & 0,381 & 0,314 & 0,229 & 0,157 & 0,148 & 0,288 & 0,229 \\
\hline Amazonas & 0,252 & 0,226 & 0,671 & 0,576 & 0,524 & 0,363 & 0,340 & 0,245 & 0,165 & 0,157 & 0,249 & 0,208 \\
\hline Roraima & 0,226 & 0,208 & 0,642 & 0,555 & 0,435 & 0,355 & 0,253 & 0,210 & 0,160 & 0,145 & 0,207 & 0,204 \\
\hline Pará & 0,244 & 0,219 & 0,709 & 0,634 & 0,537 & 0,410 & 0,341 & 0,260 & 0,175 & 0,150 & 0,295 & 0,246 \\
\hline Amapá & 0,248 & 0,228 & 0,628 & 0,526 & 0,468 & 0,321 & 0,286 & 0,200 & 0,171 & 0,159 & 0,246 & 0,221 \\
\hline Tocantins & 0,225 & 0,197 & 0,707 & 0,586 & 0,535 & 0,374 & 0,331 & 0,188 & 0,156 & 0,126 & 0,289 & 0,213 \\
\hline Maranhão & 0,252 & 0,228 & 0,767 & 0,675 & 0,618 & 0,463 & 0,433 & 0,320 & 0,187 & 0,152 & 0.317 & 0,249 \\
\hline Piaui & 0,239 & 0,215 & 0,768 & 0,679 & 0,602 & 0,451 & 0,401 & 0,290 & 0,174 & 0,133 & 0,268 & 0,219 \\
\hline Ceará & 0,238 & 0,211 & 0,737 & 0,642 & 0,576 & 0,430 & 0,368 & 0,255 & 0,171 & 0,130 & 0,243 & 0,190 \\
\hline Rio Grande do Norte & 0,231 & 0,206 & 0,713 & 0,629 & 0,571 & 0,396 & 0,333 & 0,210 & 0,164 & 0,123 & 0,214 & 0,179 \\
\hline Paraiba & 0,233 & 0,209 & 0,750 & 0,671 & 0,593 & 0,442 & 0,358 & 0,247 & 0,161 & 0,121 & 0,224 & 0,184 \\
\hline Pernambuco & 0,227 & 0,204 & 0,718 & 0,642 & 0,581 & 0,426 & 0,332 & 0,230 & 0,153 & 0,119 & 0,217 & 0,177 \\
\hline Alagoas & 0,241 & 0,218 & 0,770 & 0,688 & 0,608 & 0,442 & 0,394 & 0,278 & 0,171 & 0,137 & 0,248 & 0,207 \\
\hline Sergipe & 0,229 & 0,202 & 0,731 & 0,647 & 0,568 & 0,415 & 0,350 & 0,234 & 0,163 & 0,128 & 0,215 & 0,180 \\
\hline Bahia & 0,226 & 0,200 & 0,732 & 0,644 & 0,585 & 0,434 & 0,350 & 0,239 & 0,157 & 0,122 & 0,236 & 0,177 \\
\hline Minas Gerais & 0,206 & 0,184 & 0,659 & 0,582 & 0,471 & 0,329 & 0,208 & 0,109 & 0,127 & 0,103 & 0,141 & 0,117 \\
\hline Espírito Santo & 0,203 & 0,179 & 0,643 & 0,564 & 0,451 & 0,314 & 0,202 & 0,106 & 0,130 & 0,106 & 0,152 & 0,131 \\
\hline Rio de Janeiro & 0,192 & 0,176 & 0,570 & 0,508 & 0,432 & 0,297 & 0,143 & 0,096 & 0,110 & 0,093 & 0,105 & 0,096 \\
\hline São Paulo & 0,187 & 0,174 & 0,576 & 0,504 & 0,376 & 0,254 & 0,119 & 0,075 & 0,114 & 0,098 & 0,092 & 0,093 \\
\hline Paraná & 0,196 & 0,178 & 0,623 & 0,547 & 0,427 & 0,280 & 0,178 & 0,078 & 0,125 & 0,107 & 0,148 & 0,127 \\
\hline Santa Catarina & 0,193 & 0,169 & 0,611 & 0,526 & 0,385 & 0,242 & 0,131 & 0,052 & 0,129 & 0,105 & 0,113 & 0,107 \\
\hline Rio Grande do Sul & 0,188 & 0,172 & 0,613 & 0,543 & 0,428 & 0,300 & 0,144 & 0,074 & 0,109 & 0,092 & 0,123 & 0,107 \\
\hline Mato Grosso do Sul & 0,200 & 0,181 & 0,646 & 0,564 & 0,444 & 0,297 & 0,211 & 0,101 & 0,130 & 0,108 & 0,200 & 0,169 \\
\hline Mato Grosso & 0,199 & 0,178 & 0,663 & 0,576 & 0,433 & 0,303 & 0,209 & 0,114 & 0,135 & 0,113 & 0,225 & 0,184 \\
\hline Goiás & 0,196 & 0,176 & 0,661 & 0,569 & 0,446 & 0,299 & 0,203 & 0,097 & 0,124 & 0,105 & 0,192 & 0,167 \\
\hline Distrito Federal & 0,197 & 0,176 & 0,501 & 0,434 & 0,325 & 0,210 & 0,128 & 0,069 & 0,122 & 0,107 & 0,087 & 0,104 \\
\hline
\end{tabular}

Fonte: Elaboração própria. Informações extraídas dos microdados da amostra dos censos demográficos IBGE 2000 e 2010. 
$\mathrm{Na}$ dimensão de acesso ao conhecimento, a melhora no período entre as unidades da Federação varia entre 17,11\% e 10,53, com o melhor avanço observado em Tocantins e resultados menos rápidos para os Estados do Pará, Paraíba, Pernambuco, Alagoas e Rio de Janeiro.

A análise por regiões metropolitanas (RM) também pode ser detalhada. A Tabela 15 demonstra a evolução dos índices para as 51 subdivisões consideradas pelo IBGE em 2010. As RM do Agreste e Campina Grande são as com piores indicadores para 2000 e 2010 e, além disso, apresentam evolução no período menor do que a média das RM em geral. A RM de São Paulo também apresenta comparativamente baixa melhora no período, apenas 15,95\%. Entretanto, seu patamar em $2010(0,196)$ ainda é melhor do que a média das RM $(0,212)$ e nacional $(0,246)$. Cinco RM tiveram boa evolução no período, da ordem de 25\%: RM Belo Horizonte: Colar Metropolitano, RM Chapecó: Núcleo Metropolitano, RM Grande São Luís e RM Norte/Nordeste Catarinense: Núcleo Metropolitano.

Os resultados da dimensão condições habitacionais também são apresentados de acordo com o recorte de regiões metropolitanas. Note que, no caso desta dimensão específica, 13 entre as $51 \mathrm{RM}$ apresentam piora do indicador no período com variação percentual positiva. Entre estas, destaquese ainda a RM Norte/Nordeste Catarinense: Núcleo Metropolitano (60,4\%) e RM Vale do Itajaí: Núcleo Metropolitano (29,55\%). De outro lado, várias RM tiveram redução de vulnerabilidade em condições habitacionais da ordem de $20 \%$, ressaltando-se duas áreas de expansão metropolitana: RM Lages: Área de Expansão Metropolitana $(-26,96 \%)$ e RM Vale do Aço: Colar Metropolitano $(-24,53 \%)$.
Em relação ao comportamento de Municípios, podem-se selecionar algumas tabelas ilustrativas ${ }^{7}$. Em primeiro lugar, pode-se apontar aqueles Municípios da Federação que obtiveram as melhores reduções da vulnerabilidade no período de 2000 a 2010 (Tabela 16), muito embora em sete dos quais o crescimento da população tenha ocorrido em taxa superior à média nacional de $1,17 \%$ a.a. no período. Todavia, a média dos seus valores absolutos, 0,258 , ainda é superior à média brasileira $(0,246)$ e a população média é bastante baixa: 4.907 habitantes.

Os dez Municípios com menor vulnerabilidade no País (Tabela 17) apresentaram média populacional de 413 mil habitantes, com valores para o índice bem abaixo da média nacional, embora com crescimento no período maior que a média brasileira para seis deles.

Entre os piores Municípios em valores absolutos, cinco encontram-se no Maranhão, dois no Pará e ainda no Amazonas, Pernambuco e Roraima. Todos apresentam taxa de crescimento populacional relativamente alta no período, média de 2,73\% a.a., contra $1,17 \%$ a.a. da taxa nacional. A população média é baixa, de cerca de 15 mil habitantes. A variação de melhoria no período também é bem inferior à nacional $(-19 \%)$, da ordem de $8 \%$, em média.

Finalmente, vale notar que dois Municípios de Roraima não melhoraram sua vulnerabilidade no período: Amajari e Iracema, ambos com altas taxas de crescimento populacional (Tabela 19).

Alguns indicadores selecionados também podem ser utilizados na análise municipal. A título de ilustração, as tabelas abaixo detalham os resultados dos indicadores h3 e h13 da dimensão condições habitacionais. O primeiro (h3) refere-se à densidade de dois ou mais moradores por 
Tabela 15: Resultados por Regiões Metropolitanas

\begin{tabular}{|c|c|c|c|c|c|c|}
\hline Regiões Metropolitanas (Censo 2010) & $\begin{array}{c}\text { Índice } \\
2000\end{array}$ & $\begin{array}{l}\text { Índice } \\
2010\end{array}$ & $\begin{array}{c}\text { Diferença } \\
(\%)\end{array}$ & \begin{tabular}{c|} 
Condições \\
Habitacionais \\
2000 \\
\end{tabular} & \begin{tabular}{|c|} 
Condições \\
Habitacionais \\
2010 \\
\end{tabular} & $\begin{array}{c}\text { Diferença } \\
(\%)\end{array}$ \\
\hline Média Regiões Metropolitanas & 0,263 & 0,212 & $-19,32 \%$ & 0,116 & 0,110 & $-5,26 \%$ \\
\hline Aglomeração Urbana do Litoral Norte Rio Grande do Sul & 0,285 & 0,232 & $-18,57 \%$ & 0,123 & 0,118 & $-4,14 \%$ \\
\hline Aglomeração Urbana do Nordeste Rio Grande do Sul & 0,213 & 0,171 & $19,93 \%$ & 0,071 & 0,074 & $5,04 \%$ \\
\hline Aglomeração Urbana do Sul Rio Grande do Sul & 0,277 & 0,222 & $-20,03 \%$ & 0,083 & 0,077 & $-7,10 \%$ \\
\hline $\begin{array}{l}\text { RIDE Região Integrada de Desenvolvimento do Distrito Federal } \\
\text { e Entorno }\end{array}$ & 0,260 & 0,207 & $-20,47 \%$ & 0,138 & 0,134 & $-3,26 \%$ \\
\hline $\begin{array}{l}\text { RIDE Petrolina/Juazeiro Região Administrativa Integrada de } \\
\text { Desenvolvimento do Pólo Petrolina/PE e Juazeiro/BA }\end{array}$ & 0,373 & 0,299 & $-19,84 \%$ & 0,219 & 0,168 & $-23,04 \%$ \\
\hline $\begin{array}{l}\text { RIDE TERESINA - Região Integrada de Desenvolvimento da } \\
\text { Grande Teresina }\end{array}$ & 0,341 & 0,265 & $-22,44 \%$ & 0,168 & 0,153 & $-9,21 \%$ \\
\hline RM Agreste & 0,440 & 0,366 & $-16,93 \%$ & 0,302 & 0,255 & $-15,66 \%$ \\
\hline RM Aracaju & 0,302 & 0,235 & $-21,95 \%$ & 0,134 & 0,129 & $-3,39 \%$ \\
\hline RM Baixada Santista & 0,249 & 0,207 & $-16,90 \%$ & 0,104 & 0,101 & $-2,46 \%$ \\
\hline RM Belo Horizonte: Colar Metropolitano & 0,282 & 0,213 & $24,20 \%$ & 0,100 & 0,087 & $-13,05 \%$ \\
\hline RM Belo Horizonte: RM Belo Horizonte & 0,256 & 0,199 & $22,23 \%$ & 0,107 & 0,094 & $-12,57 \%$ \\
\hline RM Belém & 0,297 & 0,239 & $19,34 \%$ & 0,145 & 0,147 & $1,49 \%$ \\
\hline RM Campina Grande & 0,439 & 0,361 & $-17,65 \%$ & 0,297 & 0,242 & $-18,47 \%$ \\
\hline RM Campinas & 0,229 & 0,187 & $18,56 \%$ & 0,090 & 0,098 & $8,26 \%$ \\
\hline RM Carbonífera: Núcleo Metropolitano & 0,250 & 0,192 & $23,45 \%$ & 0,086 & 0,092 & $6,78 \%$ \\
\hline RM Carbonifera: Área de Expansão Metropolitana & 0,288 & 0,221 & $23,32 \%$ & 0,114 & 0,107 & $-6,33 \%$ \\
\hline RM Cariri & 0,396 & 0,310 & $-21,71 \%$ & 0,241 & 0,197 & $-18,08 \%$ \\
\hline RM Chapecó: Núcleo Metropolitano & 0,296 & 0,224 & $24,38 \%$ & 0,183 & 0,144 & $-21,00 \%$ \\
\hline RM Chapecó: Área de Expansão Metropolitana & 0,317 & 0,245 & $-22,77 \%$ & 0,210 & 0,165 & $-21,47 \%$ \\
\hline RM Curitiba & 0,236 & 0,186 & $-21,32 \%$ & 0,097 & 0,093 & $-4,21 \%$ \\
\hline RM Florianópolis: Núcleo Metropolitano & 0,217 & 0,168 & $-22,56 \%$ & 0,088 & 0,098 & $12,12 \%$ \\
\hline RM Florianópolis: Área de Expansão Metropolitana & 0,290 & 0,228 & $-21,15 \%$ & 0,148 & 0,120 & $-18,98 \%$ \\
\hline RM Fortaleza & 0,321 & 0,248 & $-22,81 \%$ & 0,158 & 0,136 & $-14,04 \%$ \\
\hline RM Foz do Rio Itajai: Núcleo Metropolitano & 0,245 & 0,186 & $-23,87 \%$ & 0,089 & 0,104 & $16,48 \%$ \\
\hline RM Foz do Rio Itajai: Área de Expansão Metropolitana & 0,259 & 0,197 & $-23,82 \%$ & 0,100 & 0,113 & $12,99 \%$ \\
\hline RM Goiânia & 0,258 & 0,205 & $-20,41 \%$ & 0,141 & 0,145 & $3,15 \%$ \\
\hline RM Grande São Luís & 0,323 & 0,243 & $-24,96 \%$ & 0,202 & 0,155 & $-23,18 \%$ \\
\hline RM Grande Vitória & 0,263 & 0,204 & $-22,53 \%$ & 0,126 & 0,116 & $-7,86 \%$ \\
\hline RM Lages: Núcleo Metropolitano & 0,274 & 0,213 & $-22,32 \%$ & 0,087 & 0,075 & $-13,64 \%$ \\
\hline RM Lages: Área de Expansão Metropolitana & 0,332 & 0,260 & $-21,79 \%$ & 0,171 & 0,125 & $-26,96 \%$ \\
\hline RM Londrina & 0,248 & 0,197 & $-20,62 \%$ & 0,112 & 0,103 & $-7,59 \%$ \\
\hline RM Macapá & 0,321 & 0,256 & $-20,13 \%$ & 0,206 & 0,197 & $-4,14 \%$ \\
\hline RM Maceió & 0,332 & 0,262 & $-21,15 \%$ & 0,164 & 0,154 & $-5,89 \%$ \\
\hline RM Manaus & 0,319 & 0,254 & $-20,44 \%$ & 0,176 & 0,159 & $-9,70 \%$ \\
\hline RM Maringá & 0,255 & 0,196 & $-23,20 \%$ & 0,135 & 0,130 & $-3,90 \%$ \\
\hline RM Natal & 0,307 & 0,240 & $-21,86 \%$ & 0,145 & 0,149 & $2,67 \%$ \\
\hline RM Norte/Nordeste Catarinense: Núcleo Metropolitano & 0,227 & 0,170 & $-24,98 \%$ & 0,052 & 0,084 & $60,40 \%$ \\
\hline $\begin{array}{l}\text { RM Norte/Nordeste Catarinense: Área de Expansão } \\
\text { Metropolitana }\end{array}$ & 0,259 & 0,203 & $-21,85 \%$ & 0,102 & 0,101 & $-0,98 \%$ \\
\hline RM Porto Alegre & 0,237 & 0,191 & $-19,22 \%$ & 0,089 & 0,090 & $0,41 \%$ \\
\hline RM Recife & 0,316 & 0,250 & $-20,84 \%$ & 0,175 & 0,151 & $-13,51 \%$ \\
\hline RM Rio de Janeiro & 0,251 & 0,205 & $-18,00 \%$ & 0,099 & 0,089 & $-10,15 \%$ \\
\hline RM Salvador & 0,283 & 0,222 & $-21,52 \%$ & 0,108 & 0,095 & $-11,67 \%$ \\
\hline RM Sudoeste Maranhense & 0,371 & 0,283 & $-23,82 \%$ & 0,216 & 0,195 & $-9,90 \%$ \\
\hline RM São Paulo & 0,233 & 0,196 & $-15,95 \%$ & 0,093 & 0,093 & $0,06 \%$ \\
\hline RM Tubarão: Núcleo Metropolitano & 0,245 & 0,187 & $-23,65 \%$ & 0,079 & 0,078 & $-0,37 \%$ \\
\hline RM Tubarão: Área de Expansão Metropolitana & 0,290 & 0,224 & $-22,72 \%$ & 0,127 & 0,119 & $-6,46 \%$ \\
\hline RM Vale do Aço: Colar Metropolitano & 0,389 & 0,298 & $-23,40 \%$ & 0,216 & 0,163 & $-24,53 \%$ \\
\hline RM Vale do Aço: RM Vale do Aço & 0,275 & 0,211 & $-23,23 \%$ & 0,098 & 0,095 & $-2,54 \%$ \\
\hline RM Vale do Itajá: Núcleo Metropolitano & 0,209 & 0,172 & $-17,64 \%$ & 0,063 & 0,081 & $29,55 \%$ \\
\hline RM Vale do Itajá: Área de Expansão Metropolitana & 0,237 & 0,195 & $-17,90 \%$ & 0,095 & 0,093 & $-2,74 \%$ \\
\hline RM Vale do Rio Cuiabá & 0,266 & 0,208 & $-21,65 \%$ & 0,147 & 0,128 & $-12,91 \%$ \\
\hline
\end{tabular}

Fonte: Elaboração própria. Informações extraídas dos microdados da amostra dos censos demográficos IBGE 2000 e 2010. 
Tabela 16: 10 Municípios com melhor variação no índice no período

\begin{tabular}{c|c|c|c|c|c|c|c}
\hline $\begin{array}{c}\text { Código } \\
\text { Município }\end{array}$ & Nome Município & $\begin{array}{c}\text { Unidade da } \\
\text { Federação }\end{array}$ & $\begin{array}{c}\text { População } \\
\text { em 2010 }\end{array}$ & $\begin{array}{c}\text { Taxa geométrica } \\
\text { crescimento população } \\
(\mathbf{2 0 1 0 - 2 0 0 0 )}\end{array}$ & indice2000 & indice2010 & $\begin{array}{c}\text { Taxa variação } \\
\text { indice (2010-2000) }\end{array}$ \\
\hline 5203203 & Barro Alto & Goiás & 8701 & $3,36 \%$ & 0,377 & 0,238 & $-36,87 \%$ \\
\hline 1712702 & Mateiros & Tocantins & 2219 & $3,03 \%$ & 0,519 & 0,328 & $-36,80 \%$ \\
\hline 4202537 & Bom Jesus & Santa Catarina & 2526 & $2,13 \%$ & 0,388 & 0,25 & $-35,57 \%$ \\
\hline 4119251 & Pinhal de São Bento & Paraná & 2620 & $0,23 \%$ & 0,446 & 0,289 & $-35,20 \%$ \\
\hline 1716505 & Pedro Afonso & Tocantins & 11542 & $2,49 \%$ & 0,372 & 0,242 & $-34,95 \%$ \\
\hline 3533205 & Nova Independència & São Paulo & 3072 & $4,06 \%$ & 0,35 & 0,235 & $-32,86 \%$ \\
\hline 3507209 & Borá & São Paulo & 805 & $0,13 \%$ & 0,308 & 0,207 & $-32,79 \%$ \\
\hline 3540309 & Pontes Gestal & São Paulo & 2523 & $-0,06 \%$ & 0,336 & 0,227 & $-32,44 \%$ \\
\hline 1600154 & Pedra Branca do Amapari & Amapá & 10773 & $10,39 \%$ & 0,473 & 0,32 & $-32,35 \%$ \\
\hline 3532207 & Narandiba & São Paulo & 4289 & $1,37 \%$ & 0,359 & 0,243 & $-32,31 \%$ \\
\hline
\end{tabular}

Fonte: Elaboração própria. Informações extraídas dos microdados da amostra dos censos demográficos IBGE 2000 e 2010.

Tabela 17: 10 Municípios com melhor valor absoluto no índice no período

\begin{tabular}{c|l|l|c|c|c|c|c}
\hline $\begin{array}{c}\text { Código } \\
\text { Município }\end{array}$ & Nome Município & $\begin{array}{c}\text { Unidade da } \\
\text { Federação }\end{array}$ & $\begin{array}{c}\text { População } \\
\text { em 2010 }\end{array}$ & $\begin{array}{c}\text { Taxa geométrica } \\
\text { crescimento população } \\
\mathbf{( 2 0 1 0 - 2 0 0 0 )}\end{array}$ & indice2000 & indice2010 & $\begin{array}{c}\text { Taxa variação } \\
\text { indice (2010-2000) }\end{array}$ \\
\hline 2605459 & Fernando de Noronha & Pernambuco & 2629 & $2,51 \%$ & 0,183 & 0,149 & $-18,58 \%$ \\
\hline 4205407 & Florianópolis & Santa Catarina & 421203 & $2,10 \%$ & 0,191 & 0,151 & $-20,94 \%$ \\
\hline 4106902 & Curitiba & Paraná & 1746896 & $0,96 \%$ & 0,2 & 0,158 & $-21,00 \%$ \\
\hline 4202008 & Balneário Camboriú & Santa Catarina & 108107 & $3,94 \%$ & 0,208 & 0,16 & $-23,08 \%$ \\
\hline 3548807 & São Caetano do Sul & São Paulo & 149571 & $0,65 \%$ & 0,191 & 0,16 & $-16,23 \%$ \\
\hline 3205309 & Vitória & Espírito Santo & 325453 & $1,08 \%$ & 0,209 & 0,161 & $-22,97 \%$ \\
\hline 4208906 & Jaraguá do Sul & Santa Catarina & 143206 & $2,82 \%$ & 0,206 & 0,162 & $-21,36 \%$ \\
\hline 4202404 & Blumenau & Santa Catarina & 309214 & $1,68 \%$ & 0,202 & 0,164 & $-18,81 \%$ \\
\hline 4305108 & Caxias do Sul & Rio Grande do Sul & 435482 & $1,91 \%$ & 0,208 & 0,165 & $-20,67 \%$ \\
\hline 3303302 & Niterói & Rio de Janeiro & 487327 & $0,59 \%$ & 0,207 & 0,165 & $-20,29 \%$ \\
\hline
\end{tabular}

Fonte: Elaboração própria. Informações extraídas dos microdados da amostra dos censos demográficos IBGE 2000 e 2010.

\section{Tabela 18: 10 Municípios com menor variação no índice no período}

\begin{tabular}{c|l|l|c|c|c|c|c}
\hline $\begin{array}{c}\text { Código } \\
\text { Município }\end{array}$ & Nome Município & $\begin{array}{c}\text { Unidade da } \\
\text { Federação }\end{array}$ & $\begin{array}{c}\text { População } \\
\text { em 2010 }\end{array}$ & $\begin{array}{c}\text { Taxa geométrica } \\
\text { crescimento população } \\
\mathbf{( 2 0 1 0 - 2 0 0 0 )}\end{array}$ & indice2000 & indice2010 & $\begin{array}{c}\text { Taxa variação } \\
\text { indice (2010-2000) }\end{array}$ \\
\hline 2109403 & Primeira Cruz & Maranhão & 13896 & $2,35 \%$ & 0,497 & 0,459 & $-7,65 \%$ \\
\hline 1303908 & São Paulo de Olivença & Amazonas & 31426 & $3,12 \%$ & 0,503 & 0,46 & $-8,55 \%$ \\
\hline 1502509 & Chaves & Pará & 21138 & $1,99 \%$ & 0,516 & 0,464 & $-10,08 \%$ \\
\hline 2609154 & Manari & Pernambuco & 18187 & $3,39 \%$ & 0,512 & 0,465 & $-9,18 \%$ \\
\hline 2102374 & Cachocira Grande & Maranhão & 8442 & $1,35 \%$ & 0,517 & 0,473 & $-8,51 \%$ \\
\hline 2101731 & Belágua & Maranhão & 6527 & $2,20 \%$ & 0,534 & 0,477 & $-10,67 \%$ \\
\hline 1504505 & Melgaço & Pará & 24789 & $1,64 \%$ & 0,516 & 0,477 & $-7,56 \%$ \\
\hline 2104081 & Fernando Falcão & Maranhão & 9180 & $6,65 \%$ & 0,51 & 0,48 & $-5,88 \%$ \\
\hline 2106359 & Marajá do Sena & Maranhão & 8045 & $1,17 \%$ & 0,508 & 0,48 & $-5,51 \%$ \\
\hline 1400704 & Uiramutã & Roraima & 8147 & $3,45 \%$ & 0,524 & 0,502 & $-4,20 \%$ \\
\hline
\end{tabular}

Fonte: Elaboração própria. Informações extraídas dos microdados da amostra dos censos demográficos IBGE 2000 e 2010. 
Tabela 19: 10 Municípios com pior valor absoluto no índice no período

\begin{tabular}{l|l|l|c|c|c|c|c}
\hline $\begin{array}{c}\text { Código } \\
\text { Municipio }\end{array}$ & Nome Municipio & $\begin{array}{c}\text { Unidade da } \\
\text { Federação }\end{array}$ & $\begin{array}{c}\text { População } \\
\text { em 2010 }\end{array}$ & $\begin{array}{c}\text { Taxa geométrica } \\
\text { crescimento população } \\
\mathbf{( 2 0 1 0 - 2 0 0 0 )}\end{array}$ & indice2000 & indice2010 & $\begin{array}{c}\text { Taxa variação } \\
\text { indice (2010-2000) }\end{array}$ \\
\hline 1400027 & Amajari & Roraima & 9330 & $5,83 \%$ & 0,429 & 0,439 & $2,33 \%$ \\
\hline 1400282 & Iracema & Roraima & 8676 & $6,14 \%$ & 0,374 & 0,374 & $0,00 \%$ \\
\hline 5108303 & União do Sul & Mato Grosso & 3767 & $-1,07 \%$ & 0,278 & 0,274 & $-1,44 \%$ \\
\hline 4305447 & Chuvisca & Rio Grande do Sul & 4944 & $0,94 \%$ & 0,34 & 0,331 & $-2,65 \%$ \\
\hline 4213104 & Piratuba & Santa Catarina & 4786 & $-1,92 \%$ & 0,238 & 0,23 & $-3,36 \%$ \\
\hline 1400704 & Uiramutã & Roraima & 8147 & $3,45 \%$ & 0,524 & 0,502 & $-4,20 \%$ \\
\hline 5108501 & Vera & Mato Grosso & 10235 & $1,23 \%$ & 0,28 & 0,268 & $-4,29 \%$ \\
\hline 1505908 & Porto de Moz & Pará & 33951 & $3,73 \%$ & 0,46 & 0,435 & $-5,43 \%$ \\
\hline 2106359 & Marajá do Sena & Maranhão & 8045 & $1,17 \%$ & 0,508 & 0,48 & $-5,51 \%$ \\
\hline 2104081 & Fernando Falcão & Maranhão & 9180 & $6,65 \%$ & 0,51 & 0,48 & $-5,88 \%$ \\
\hline
\end{tabular}

Fonte: Elaboração própria. Informações extraídas dos microdados da amostra dos censos demográficos IBGE 2000 e 2010.

dormitório, enquanto o segundo (h13) reflete a necessidade de deslocar-se a outro município para estudar ou trabalhar. 393 Municípios, por exemplo, apresentam valor nulo para o indicador h3 em 2010, o que indica que, na amostra de famílias entrevistadas pelo censo domiciliar, não havia nenhuma ocorrência nesses Municípios para domicílios com densidade maior ou igual a dois moradores por dormitório. De outro lado, Municípios no Amazonas, Pará e Roraima apresentam índices acima de 0,4 nesse indicador ${ }^{8}$.

Em relação à necessidade de mobilidade intermunicipal, vários Municípios apresentam variação maior que $2000 \%$ no período (Tabela 20). Finalmente, a Tabela 21 apresenta 11 Municípios - próximos a grandes centros - nos quais o indicador de mobilidade fica acima de 0,7 . Os três piores resultados são para Municípios em São Paulo.

O recorte espacial mais detalhado possível é a análise das áreas de ponderação. A título de exemplo, dado o bom desempenho do Distrito Federal no resultado do índice, optou-se por ilustrar as possibilidades da escala maior com Brasília e seu entorno (Figura 1). Note que o DF obtém, na média, valor de 0,183 no índice de vulnerabilidade. De todo modo, se considerados os Municípios limítrofes ao DF, que no conjunto compõem a Região Integrada do Distrito Federal e Entorno, esse valor já aumenta para 0,207. Esses números médios não permitem observar a heterogeneidade existente quando desagregada por áreas de ponderação. De fato, os dados da figura 1 indicam que a região central de Brasília, o Plano Piloto, o Lago Sul, o Park Way ou Águas Claras, apresentam índices de vulnerabilidade bem melhores, da ordem de 0,8 a 1,4. Regiões urbanas vizinhas conurbadas, por sua vez, apresentam valores mais altos, da ordem de 0,28 a 0,32 , substancialmente maiores que a média nacional $(0,24)^{9}$.

Finalmente, a título de ilustração, apresenta-se o cartograma para o índice completo para áreas de ponderação para o ano de 2010 (Figura 2). 
Tabela 20: 20 Municípios com maior variação no indicador h13 no período

\begin{tabular}{l|l|r|r|r|r|c|c}
\hline & & \multicolumn{2}{|c|}{2000} & \multicolumn{2}{|c}{2010} & \multicolumn{2}{c}{$\%$} \\
\hline Município & Unidade Federação & H3 & H13 & H3 & H13 & Diferença H3 & Diferença H13 \\
\hline Bertolínia & Piauí & 0,027 & 0,002 & 0,011 & 0,229 & $-59,4 \%$ & $10491,20 \%$ \\
\hline Brasnorte & Mato Grosso & 0,085 & 0,001 & 0,046 & 0,070 & $-45,6 \%$ & $5218,32 \%$ \\
\hline Alvarães & Amazonas & 0,498 & 0,002 & 0,297 & 0,066 & $-40,3 \%$ & $3675,29 \%$ \\
\hline Paial & Santa Catarina & 0,014 & 0,009 & 0,009 & 0,308 & $-35,5 \%$ & $3355,51 \%$ \\
\hline Leoberto Leal & Santa Catarina & 0,002 & 0,004 & 0,000 & 0,140 & $-100,0 \%$ & $3221,90 \%$ \\
\hline Portel & Pará & 0,505 & 0,001 & 0,461 & 0,042 & $-8,8 \%$ & $3200,78 \%$ \\
\hline Milton Brandão & Piauí & 0,052 & 0,003 & 0,022 & 0,090 & $-58,1 \%$ & $2955,44 \%$ \\
\hline Pau D'Arco & Tocantins & 0,068 & 0,004 & 0,034 & 0,116 & $-50,4 \%$ & $2913,73 \%$ \\
\hline Porteirão & Goiás & 0,019 & 0,010 & 0,000 & 0,276 & $-100,0 \%$ & $2724,05 \%$ \\
\hline Montividiu do Norte & Goiás & 0,028 & 0,006 & 0,017 & 0,162 & $-40,3 \%$ & $2714,81 \%$ \\
\hline Monte Alegre dos Campos & Rio Grande do Sul & 0,049 & 0,008 & 0,005 & 0,228 & $-90,8 \%$ & $2580,21 \%$ \\
\hline Santana do Piauí & Piauí & 0,013 & 0,013 & 0,008 & 0,333 & $-37,9 \%$ & $2565,12 \%$ \\
\hline Capixaba & Acre & 0,168 & 0,003 & 0,123 & 0,084 & $-26,9 \%$ & $2535,00 \%$ \\
\hline Santa Carmem & Mato Grosso & 0,020 & 0,009 & 0,008 & 0,234 & $-62,6 \%$ & $2512,93 \%$ \\
\hline Capinzal do Norte & Maranhão & 0,054 & 0,005 & 0,024 & 0,130 & $-56,4 \%$ & $2495,62 \%$ \\
\hline Porto Acre & Acre & 0,206 & 0,006 & 0,123 & 0,165 & $-40,5 \%$ & $2494,18 \%$ \\
\hline Carrasco Bonito & Tocantins & 0,071 & 0,008 & 0,021 & 0,215 & $-70,3 \%$ & $2478,90 \%$ \\
\hline Campo Novo de Rondônia & Rondônia & 0,130 & 0,003 & 0,018 & 0,064 & $-85,9 \%$ & $2433,86 \%$ \\
\hline Alvorada de Minas & Minas Gerais & 0,043 & 0,005 & 0,016 & 0,135 & $-61,4 \%$ & $2393,37 \%$ \\
\hline Piratuba & Santa Catarina & 0,024 & 0,013 & 0,000 & 0,314 & $-100,0 \%$ & $2353,55 \%$ \\
\hline & & & & & \\
\hline
\end{tabular}

Fonte: Elaboração própria. Informações extraídas dos microdados da amostra dos censos demográficos IBGE 2000 e 2010.

Tabela 21: 11 Municípios com maior valor absoluto no indicador h13 no período

\begin{tabular}{l|l|c|c|c|c|c|c}
\hline & & \multicolumn{2}{|c|}{2000} & \multicolumn{2}{c|}{2010} & \multicolumn{2}{c}{$\%$} \\
\hline Município & Unidade Federação & H3 & H13 & H3 & H13 & Diferença H3 & Diferença H13 \\
\hline Santa Ernestina & São Paulo & 0,033 & 0,673 & 0,004 & 0,805 & $-87,7 \%$ & $19,46 \%$ \\
\hline Santa Lúcia & São Paulo & 0,008 & 0,622 & 0,004 & 0,797 & $-47,0 \%$ & $28,01 \%$ \\
\hline Catiguá & São Paulo & 0,009 & 0,602 & 0,004 & 0,753 & $-59,6 \%$ & $25,22 \%$ \\
\hline Raposos & Minas Gerais & 0,023 & 0,627 & 0,012 & 0,752 & $-48,9 \%$ & $19,78 \%$ \\
\hline Rio Grande da Serra & São Paulo & 0,081 & 0,645 & 0,026 & 0,746 & $-67,6 \%$ & $15,67 \%$ \\
\hline Santa Cruz de Minas & Minas Gerais & 0,018 & 0,555 & 0,004 & 0,726 & $-76,9 \%$ & $30,81 \%$ \\
\hline Jandira & São Paulo & 0,062 & 0,616 & 0,029 & 0,722 & $-53,1 \%$ & $17,20 \%$ \\
\hline Alvorada & Rio Grande do Sul & 0,040 & 0,681 & 0,011 & 0,721 & $73,1 \%$ & $5,83 \%$ \\
\hline Ibirité & Minas Gerais & 0,041 & 0,661 & 0,012 & 0,721 & $-70,8 \%$ & $9,01 \%$ \\
\hline Almirante Tamandaré & Paraná & 0,047 & 0,672 & 0,016 & 0,720 & $-66,1 \%$ & $7,05 \%$ \\
\hline Francisco Morato & São Paulo & 0,104 & 0,659 & 0,045 & 0,710 & $-56,3 \%$ & $7,84 \%$ \\
\hline
\end{tabular}

Fonte: Elaboração própria. Informações extraídas dos microdados da amostra dos censos demográficos IBGE 2000 e 2010. 


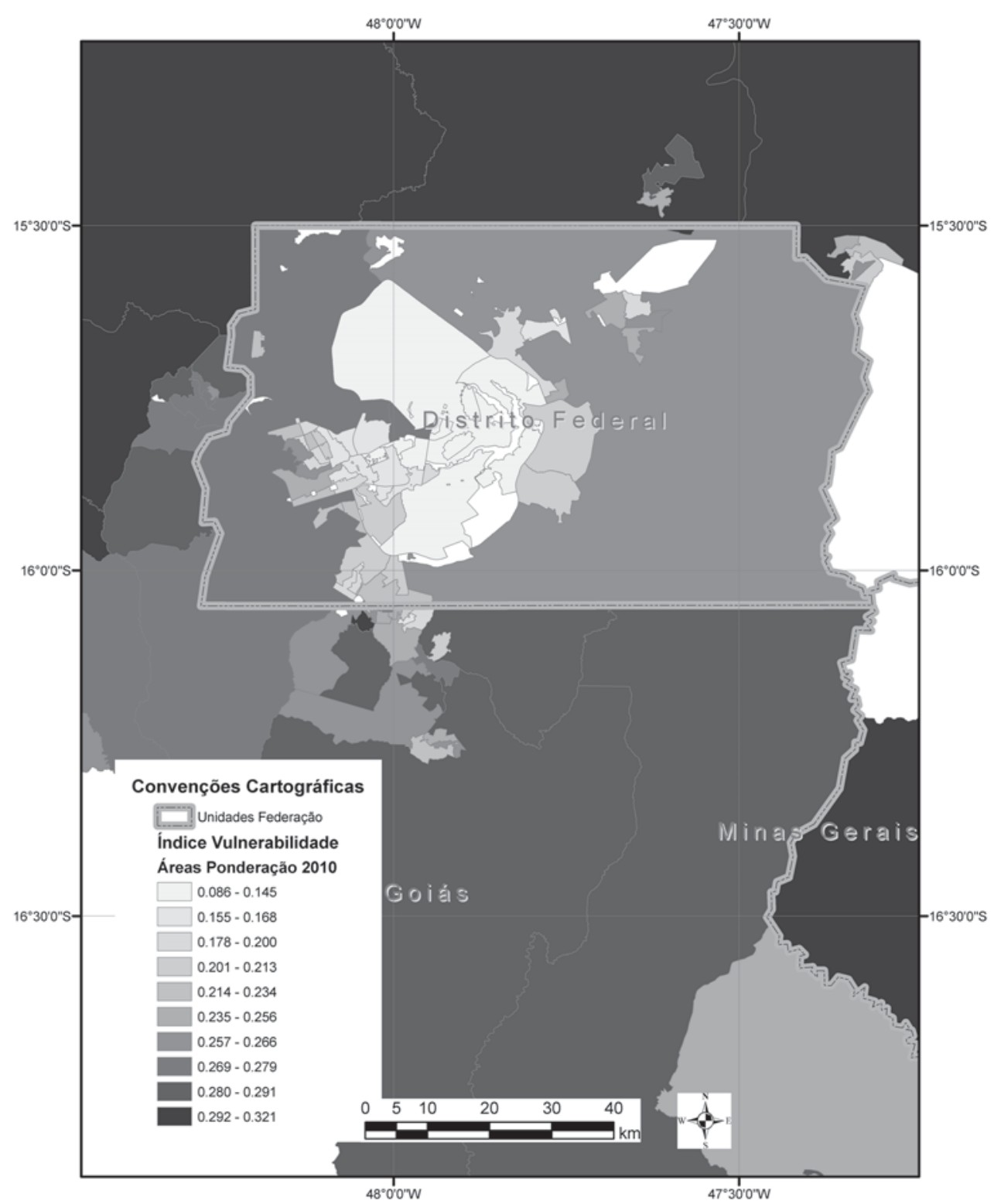

Fonte: Elaboração própria. Informações extraídas dos microdados da amostra do censo demográfico IBGE 2010

Figura 1: Índice de vulnerabilidade 2010. Distrito Federal e entorno 


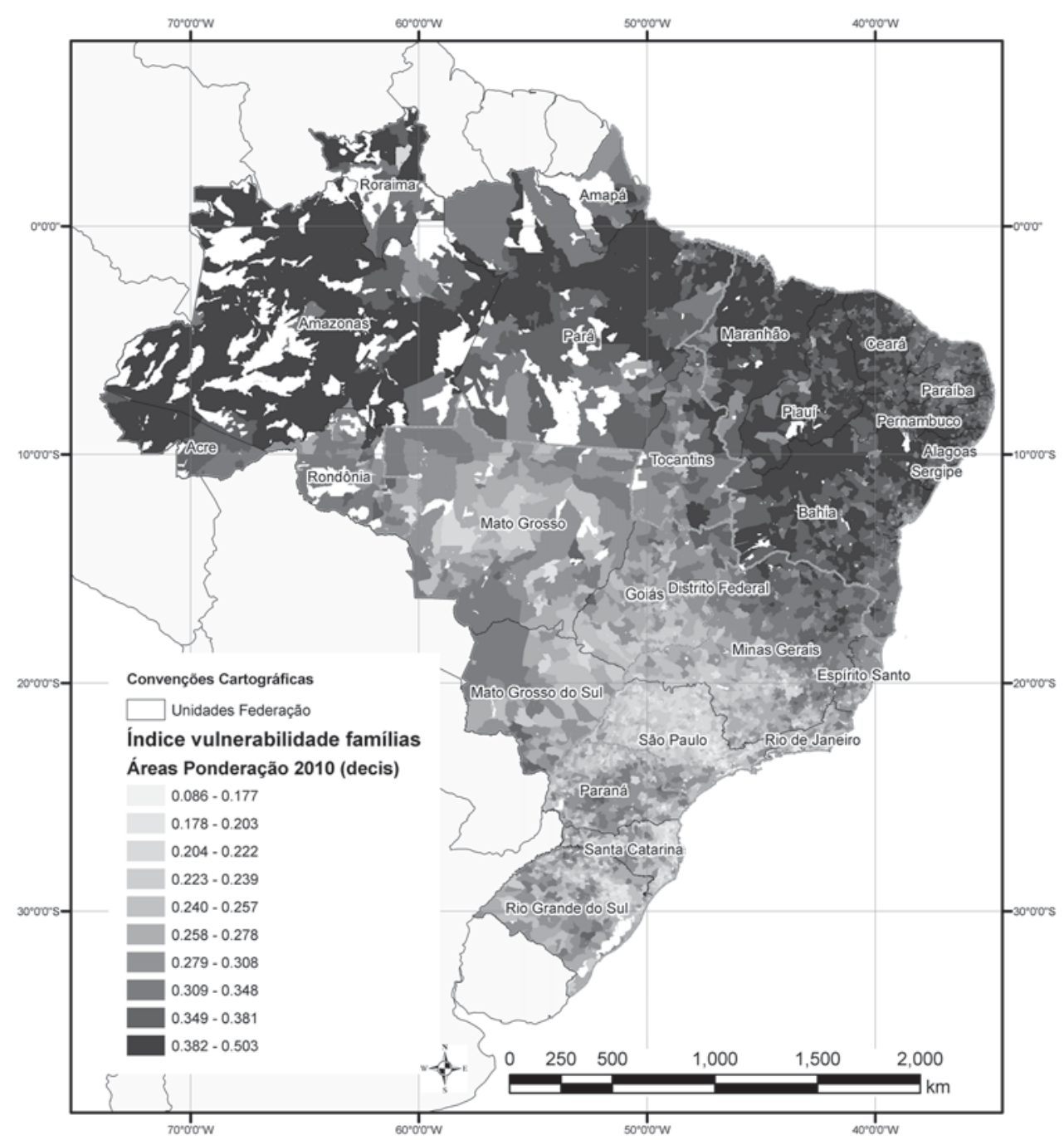

Fonte: Elaboração própria. Informações extraídas dos microdados da amostra do censo demográfico IBGE 2010.

Figura 2: Índice vulnerabilidade das famílias por áreas de ponderação 
Outros resultados, algumas limitações e ponderações

Dado que a elaboração deste trabalho baseou-se em construção de metodologia anterior, a própria manipulação dos dados, indicadores, dimensões e resultados desperta algumas considerações mais gerais que imaginamos seriam válidas para compartilhar com o leitor. Em especial, seria possível pensar no rearranjo de alguns indicadores em dimensões distintas. Há questões referentes à capacidade de consumo, por exemplo, abrigadas nas dimensões de condições habitacionais e acesso ao trabalho.

Outra característica que reforça, em certo sentido, a análise proposta (de independência entre os componentes do índice) é que a correlação entre as dimensões (Tabela 22) é relativamente baixa. Note que, à exceção da correlação entre acesso ao conhecimento e acesso ao trabalho, todos os outros pares apresentam valores abaixo de 0,55 . Isso indica que não está se mensu- rando elementos repetidos nas várias dimensões, mas elementos distintos, fato que, de certo modo, reforça o caráter multidimensional da análise e as várias possibilidades da qualidade de vida ser influenciada por grande número de fatores. As relações de correlação apresentam magnitudes similares para os dois anos da análise.

Outra possibilidade que o modo de construção do índice nos permite realizar é a análise da desigualdade do indicador internamente a cada unidade da Federação. Como o índice é calculado por domicílio, para cada unidade da Federação é possível calcular a desigualdade do valor do índice entre as famílias de determinado recorte geográfico de análise. Ou seja, para dada unidade da Federação, é possível identificar se os valores do índice das famílias daquela unidade são mais homogêneos ou mais heterogêneos. Em outras palavras, é possível calcular o coeficiente de Gini ${ }^{10} \mathrm{da}$ variável calculada, o índice, para cada unidade da Federação. Os resultados estão apresentados na Tabela 23.

Tabela 22: Correlações entre as dimensões

\begin{tabular}{|c|c|c|c|c|c|c|}
\hline 2010 & vulnerabilidade & conhecimento & trabalho & recursos & infanto-juvenil & $\begin{array}{l}\text { condiçōes } \\
\text { habitacionais }\end{array}$ \\
\hline vulnerabilidade & & 0,20 & 0,16 & 0,18 & 0,34 & 0,06 \\
\hline conhecimento & 0,20 & & 0,55 & 0,33 & 0,09 & 0,27 \\
\hline trabalho & 0,16 & 0,55 & & 0,50 & $-0,03$ & 0,21 \\
\hline recursos & 0,18 & 0,33 & 0,50 & & 0,28 & 0,31 \\
\hline infanto-juvenil & 0,34 & 0,09 & $-0,03$ & 0,28 & & 0,11 \\
\hline $\begin{array}{c}\text { condições } \\
\text { habitacionais }\end{array}$ & 0,06 & 0,27 & 0,21 & 0,31 & 0,11 & \\
\hline 2000 & vulnerabilidade & conhecimento & trabalho & recursos & infanto-juvenil & $\begin{array}{c}\text { condições } \\
\text { habitacionais }\end{array}$ \\
\hline vulnerabilidade & & 0,19 & 0,17 & 0,26 & 0,3 & 0,13 \\
\hline conhecimento & 0,19 & & 0,51 & 0,45 & 0.12 & 0,39 \\
\hline trabalho & 0,17 & 0,51 & & 0,50 & 0,06 & 0,25 \\
\hline recursos & 0,26 & 0,45 & 0,50 & & 0,30 & 0,43 \\
\hline infanto-juvenil & 0,3 & 0,12 & 0,06 & 0,30 & & 0,12 \\
\hline $\begin{array}{c}\text { condiçôes } \\
\text { habitncionais }\end{array}$ & 0,13 & 0,39 & 0,25 & 0,43 & 0,12 & \\
\hline
\end{tabular}

Fonte: Elaboração própria. 
Tabela 23: Coeficiente de GINI do índice de vulnerabilidade das famílias, por UF

\begin{tabular}{|c|c|c|c|}
\hline UF & Gini 2000 & Gini 2010 & Dif. Gini do Índice \\
\hline Rondônia & 0,245 & 0,269 & $9,8 \%$ \\
\hline Acre & 0,251 & 0,283 & $13,0 \%$ \\
\hline Amazonas & 0,261 & 0,297 & $13,9 \%$ \\
\hline Roraima & 0,290 & 0,305 & $5,1 \%$ \\
\hline Pará & 0,232 & 0,262 & $12,7 \%$ \\
\hline Amapá & 0,268 & 0,296 & $10,1 \%$ \\
\hline Tocantins & 0,236 & 0,281 & $19,1 \%$ \\
\hline Maranhão & 0,192 & 0,242 & $26,2 \%$ \\
\hline Piauí & 0,206 & 0,251 & $21,6 \%$ \\
\hline Ceará & 0,223 & 0,259 & $15,9 \%$ \\
\hline Rio Grande do Norte & 0,238 & 0,270 & $13,3 \%$ \\
\hline Paraíba & 0,219 & 0,254 & $16,0 \%$ \\
\hline Pernambuco & 0,235 & 0,264 & $12,3 \%$ \\
\hline Alagoas & 0,213 & 0,253 & $18,7 \%$ \\
\hline Sergipe & 0,229 & 0,268 & $17,1 \%$ \\
\hline Bahia & 0,234 & 0,269 & $15,4 \%$ \\
\hline Minas Gerais & 0,273 & 0,288 & $5,7 \%$ \\
\hline Espírito Santo & 0,271 & 0,292 & $7,8 \%$ \\
\hline Rio de Janeiro & 0,297 & 0,306 & $2,9 \%$ \\
\hline São Paulo & 0,302 & 0,309 & $2,3 \%$ \\
\hline Paraná & 0,284 & 0,297 & $4,5 \%$ \\
\hline Santa Catarina & 0,284 & 0,297 & $4,5 \%$ \\
\hline Rio Grande do Sul & 0,286 & 0,297 & $3,7 \%$ \\
\hline Mato Grosso do Sul & 0,268 & 0,289 & $8,0 \%$ \\
\hline Mato Grosso & 0,262 & 0,280 & $7,0 \%$ \\
\hline Goiás & 0,258 & 0,274 & $6,3 \%$ \\
\hline Distrito Federal & 0,346 & 0,342 & $-1,0 \%$ \\
\hline Brasil & 0,288 & 0,306 & $6,0 \%$ \\
\hline
\end{tabular}

Fonte: Elaboração própria. 
Note que os Estados com maior vulnerabilidade (MA, PI, AL) também apresentam maior homogeneidade entre as famílias componentes (coeficientes de 0,$242 ; 0,251$ e 0,253 ; respectivamente). Ou seja, a vulnerabilidade entre as famílias se encontra em patamares altos para o conjunto das famílias, com menos disparidade entre os níveis de vulnerabilidade. De outro lado, unidades da Federação com menor vulnerabilidade apresentam maior variabilidade entre as famílias.

A análise da Figura 3 - que demonstra a correlação entre níveis de vulnerabilidade e o coeficiente calculado - em conjunto com o dado da evolução desse coeficiente no período 2000-2010 explicita o fato de que, muito embora haja ganhos significativos na melhoria da vulnerabilidade das famílias na década, é crescente a desigualdade dessa vulnerabilidade, ou seja, proporcionalmente há mais famílias com menor e com maior vulnerabilidade. Esse aumento se verifica com maior magnitude nos Estados do Norte e Nordeste. O Distrito Federal foi a única unidade da Federação no período a apresentar redução nesse índice, embora permaneça em patamar bastante superior às demais UF.

\section{Considerações finais}

Este texto buscou trazer ao leitor informações acerca da vulnerabilidade das famílias escalonadas do geral para o específico. Observa-se, no conjunto, melhora considerável com diminuição da vulnerabilidade das famílias no período 2000 a 2010. Essa melhora se relativiza e é heterogênea na medida em que se analisam dimensões distintas da vulnerabilidade e indicadores específicos. De fato, as dimensões relacionadas ao trabalho e renda melhoraram proporcionalmente mais que a vulnerabilidade social ou o acesso ao conhecimento. Foi diferenciada também a melhoria entre os Estados da Federação e

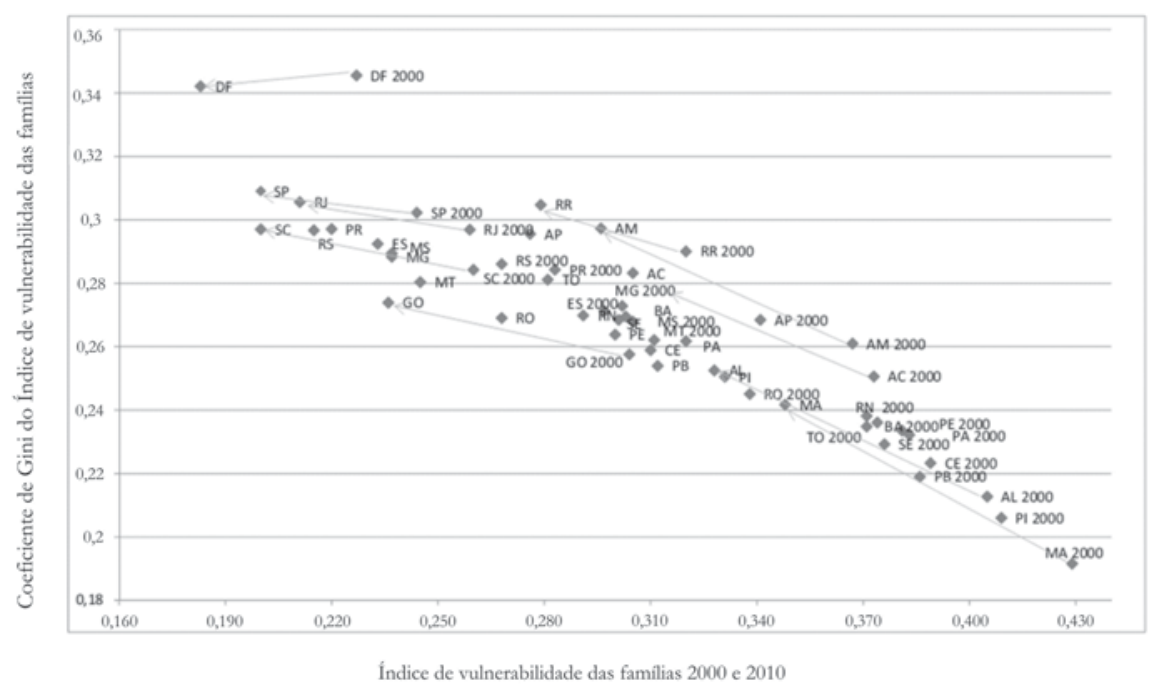

Fonte: Elaboração própria.

Figura 3: Correlação entre índice de vulnerabilidade das famílias e o coeficiente de GINI do índice, por UF 
os Municípios. Por fim, fica fácil ver que mesmo porções do território com baixa vulnerabilidade apresentam heterogeneidades típicas da dicotomia centro-periferia ou urbano-rural.

De modo geral, o Nordeste e o Norte estão em patamares diferenciados em relação ao restante do país. E no Nordeste, os Estados de Maranhão, Piauí e Alagoas merecem atenção especial dos gestores de políticas públicas.
Espera-se que, com esse conjunto informacional, contribua-se para a publicidade de fatores socioeconômicos múltiplos subjacentes aos efeitos ora apresentados, de modo que se possa esclarecer à opinião pública, bem como aos tomadores de decisão de política pública.

(Artigo recebido em setembro de 2012. Versão final em junho de 2013).

\section{Notas}

${ }^{1}$ Veja, por exemplo, Neri (2010).

2 Além dos inúmeros resultados ora apresentados, tabelas completas (de Municípios, por exemplo) podem ser solicitadas ao autor.

${ }^{3}$ Essa abordagem pode ser criticada por não considerar o caráter de subsistência e redes sociais presentes nas áreas rurais (LOPES; MACEDO; MACHADO, 2003).

${ }^{4}$ Em relação à questão ambiental, ressalte-se que apenas no quesito habitação incluem-se temas como saneamento básico e tratamento adequado de resíduos sólidos. Essa limitação no trato da questão ambiental deriva da restrição imposta pelo conjunto de perguntas feitas na amostra do censo.

${ }^{5}$ Dado que se trata de índices de vulnerabilidades variando entre 0 e 1 , valores mais próximos de 1 indicam maiores vulnerabilidades, enquanto valores baixos próximos a zero, indicam reduzida vulnerabilidade.

${ }^{6}$ Regiões Integradas de Desenvolvimento: RIDE DF - Região Integrada de Desenvolvimento do Distrito Federal e Entorno; RIDE TERESINA - Região Integrada de Desenvolvimento da Grande Teresina e RIDE PETROLINA/JUAZEIRO - Região Administrativa Integrada de Desenvolvimento do Pólo Petrolina/PE e Juazeiro/BA.

${ }^{7}$ A tabela completa está disponível por solicitação ao autor.

${ }^{8}$ Limoeiro do Ajuru, Pará; Oeiras do Pará, Pará; São Paulo de Olivença, Amazonas; Porto de Moz, Pará; Breves, Pará; São Gabriel da Cachoeira, Amazonas; Tonantins, Amazonas, Barreirinha, Amazonas; Amajari, Roraima; Melgaço, Pará; Jordão, Acre; Barcelos, Amazonas; Portel, Pará; Maraã, Amazonas; Normandia, Roraima; Santa Isabel do Rio Negro, Amazonas; Bagre, Pará; Uiramutã, Roraima.

${ }^{9}$ A área de ponderação com melhor resultado absoluto 0,086 fica em Brasília. As duas seguintes em Belo Horizonte. A pior no Pará, a segunda pior em Roraima e a terceira no Rio de Janeiro.

${ }^{10}$ Cálculos feitos com o Índice de Theil T também confirmaram aumento na inequalidade dos valores dos índices no período analisado (0,139 em 2000 para 0,155 em 2010). 


\section{Referências bibliográficas}

Barros, R. P.; Carvalho, M.; Franco, S. Pobreza Multidimensional no Brasil. Textos para discussão do IPE $A$, v. 1227, p. 40, 2006.

Barros, R. P. de; Foguel, M. N.; Ulyssea, G. Desigualdade de Renda no Brasil: uma análise da queda recente. Brasilia: Instituto de Pesquisa Economica Aplicada/IPEA, 2007.

Castro, A. L. C. de. Manual de planejamento em defesa civil. Brasília: Ministério da Integração Nacional-MI/Secretaria de Defesa Civil, v.1, 1999.

IBGE. Censo Demográfico 2010: características gerais da população, religião e pessoas com deficiência. Rio de Janeiro: IBGE, 2010.

Lopes, H. M.; Macedo, P. B. R.; Machado, A. F. Indicador de pobreza: aplicação de uma abordagem multidimensional ao caso brasileiro. [S.l.] Cedeplar, Universidade Federal de Minas Gerais, 2003. Disponivel em: < http://ideas.repec.org/p/cdp/texdis/td223.html>. Acesso em: 25 jun. 2013.

NAHAS, M. I. P. O Sistema de indicadores intraurbanos de Belo Horizonte para gestão e monitoramento da qualidade de vida urbana: 1993-2000. Pensar BH: Política Social, 2002.

Neri, M. C. A Nova Classe Média: o lado brilhante dos pobres. Rio de Janeiro: FGV/ IBRE CPS, 2010.

Osorio, R. G.; SOARES, S.; SouZA, P. H. G. F. DE. Erradicar a pobreza extrema: um objetivo ao alcance do Brasil. [S.1.] Instituto de Pesquisa Econômica Aplicada-IPEA, 2011.

Queiroz, Bernardo L.; Golgher, André B. Human Capital Differentials across Municipalities and States in Brazil. Population Review, v. 47, n. 2, 2008.

RochA, S.; VILLELA, R. Caracterização da subpopulação pobre metropolitana nos anos 80: resultados de uma análise multivariada. Revista Brasileira de Economia, v. 44, n. 1, p. 35-52, 1990.

SÁNCHEZ, A. I.; BERTOLOZZI, M. R. Pode o conceito de vulnerabilidade apoiar a construção do conhecimento em saúde coletiva? Ciência \& Saúde Coletiva, v. 12, n. 2, p. 319-324, 2007. SOARES, S. S. D. O ritmo de queda na desigualdade no Brasil é adequado? Evidências do contexto histórico e internacional. IPEA: Texto para discussão, v. 1339, p. 21, 2008.

são, v. 1381, 2009.

Metodologias para estabelecer a linha de pobreza.IPEA: Texto para discus- 


\title{
Resumo - Resumen - Abstract
}

Índice de vulnerabilidade das famílias: resultados espacializados para a década de 2000 no Brasil e regiões

\author{
Bernardo Alves Furtado
}

O objetivo deste texto é apresentar de forma imediata, mas também precisa e espacialmente detalhada, a situação de vulnerabilidade das famílias brasileiras a partir das respostas aos censos demográficos de 2000 e 2010. Dessa forma, espera-se oferecer aos gestores públicos em específico e a pesquisadores e ao público em geral material de acesso e referência ao conjunto - por vezes complexo e inacessível - de inferências possíveis a partir dos questionários dos microdados da amostra dos censos. A metodologia utilizada para construção de indicadores sintéticos está fartamente descrita na literatura anterior. A partir da construção de indicadores que denotam presença ou ausência de vulnerabilidades, agregam-se seis dimensões de análise, então reunidas no índice geral que pode ser descrito para o País, Estados, Municípios e áreas intraurbanas. Os resultados indicam que a vulnerabilidade das famílias brasileiras no período recuou em média $20 \%$. Esse comportamento, todavia, é heterogêneo entre as dimensões analisadas, seus indicadores, as regiões e Estados do País. É exatamente na identificação dessa heterogeneidade dos efeitos percebidos na década que se encontra a contribuição do texto.

Palavras-chave: índice; vulnerabilidade; famílias

Los índices de vulnerabilidad de las familias: resultados espacializados para la década de 2000 en Brasil y regiones

Bernardo Alves Furtado

El objetivo de este trabajo es presentar una investigación inmediata, pero también espacialmente precisa y detallada de la situación de vulnerabilidad de las familias brasileñas de las respuestas a los censos de 2000 y 2010. Por lo tanto, se espera ofrecer los gestores públicos e investigadores en específico y el acceso del público en general material de referencia para el conjunto - a veces complejo y de difícil acceso - para las inferencias posibles acerca de los cuestionarios de los censos de muestras de microdados. La metodología utilizada para la construcción de indicadores sintéticos se describe ampliamente en la literatura. A partir de la construcción de indicadores que denotan la presencia o ausencia de vulnerabilidades, suman seis dimensiones de análisis, a continuación, se reunieron en el índice que puede ser descrito por la nación, estados, condados y áreas intraurbanas. Los resultados indican que la vulnerabilidad de las familias brasileñas en el período cayó un $20 \%$ en promedio. Este comportamiento, sin embargo, es heterogéneo entre las dimensiones analizadas, sus indicadores, regiones y estados. Es precisamente esta heterogeneidad en la identificación de los efectos percibidos en la década que es la aportación del texto.

Palabras clave: índice; la vulnerabilidad; las familias 
Families vulnerability index: spatialized results to the 2000s in Brazil and regions Bernardo Alves Furtado

The objective of this paper is to make available information - precisely and spatially detailed - about families' vulnerabilities derived from questionnaires' answers of census data for 2000 and 2010. In doing so this paper fulfills the task of providing reference data - occasionally complex - accessible to public authorities and researchers so that inferences can be made from the micro data of the census sample interviews. The methodology used is by and large detailed in the literature. The actual construction of the indicators is based on the analysis of presence or absence of vulnerabilities within families across six different dimensions, detailed for the country, states, municipalities and intraurban detail. Results indicate that Brazilian families' vulnerability reduced by nearly $20 \%$ in the period on average. This behavior, however, is heterogeneous among the dimensions analyzed, the indicators or the regions and states of the country. It is exactly the analysis of this perceived heterogeneity in the decade that makes the core of the contribution of this paper.

Keywords: index; vulnerability; families

Bernardo Alves Furtado

É doutor em Geociências pela Utrecht University (2009), Diretor Adjunto e Técnico de Planejamento e Pesquisa da Diretoria de Estudos e Políticas Regionais, Urbanas e Ambientais (Dirur) do Instituto de Pesquisa Econômica Aplicada (Ipea).Contato: bernardo.furtado@ipea.gov.br 